\title{
Mini-Oct and Oct-2c: Two Novel, Functionally Diverse Murine Oct-2 Gene Products Are Differentially Expressed in the CNS
}

\author{
A. S. Stoykova, ${ }^{*}$ S. Sterrer, J. R. Erselius, \\ A. K. Hatzopoulos, ${ }^{\dagger}$ and P. Gruss \\ Department of Molecular Cell Biology \\ Max-Planck-Institute of Biophysical Chemistry \\ 3400 Göttingen \\ Germany
}

\section{Summary}

We report that two novel alternatively spliced products of the murine Oct-2 gene encode Mini-Oct (Oct-2d), a protein consisting of almost only the POU domain, and Oct-2c, a protein lacking the last 12 amino acids of Oct2a. Ectopic expression in HeLa cells shows that Oct-2c is a transactivator, whereas Mini-Oct fails to transactivate if the octamer motif is in a promotor position next to TATA box. Mini-Oct can repress the transcriptional signal generated by endogenous octamer factors in F9 cells. It seems that Mini-Oct has the potential to serve as a transcriptional modulator for genes regulated by different octamer-binding factors. In situ hybridization reveals that Mini-Oct expression follows the general pattern of other known Oct-2 transcripts. However, it is absent from the Purkinje cell layer in the cerebellum of adult mice, and strong expression is observed in the developing nasal neuroepithelium and primary spermatids. Differential expression patterns of the Oct-2 transcripts with different transactivation/repression capacities of the encoded proteins may have a specific role in gene expression in the developing nervous system and in adult brain.

\section{Introduction}

Recent studies on Oct-1 (Singh et al., 1986; Sturm et al., 1988), Oct-2 (Clerc et al., 1988; Ko et al., 1988; Landolfi et al., 1986; Müller et al., 1988; Scheidereit et al., 1988), and Pit-1/GHF-1 (Bodner et al., 1988; Ingraham et al., 1988) show that these transcription factors and the unc- 86 gene product contain a conserved DNAbinding domain of 150-160 amino acids, designated as the POU domain (Herr et al., 1988). The POU domain consists of two regions separated by a short (15-27 amino acids) nonconserved linker. The C-proximal region of the POU domain, called the POU homeodomain, is homologous in all four proteins. It is related to the homeobox domain, previously identified in Drosophila developmental control genes (McGinnis et al., 1984; Scott and Weiner, 1984; Gehring, 1987), which contains a helix-turn-helix motif similar to that of bacterial repressor proteins and present in many

\footnotetext{
* On leave of absence from the Bulgarian Academy of Sciences, Institute of Molecular Biology, Sofia, Bulgaria.

+Present address: Department of Biology, Massachusetts Institute of Technology, Cambridge, Massachusetts 02139.
}

transcription factors (Laughon and Scott, 1984; Sturm et al., 1988). The $\mathrm{N}$-proximal region, referred to as the POU-specific domain, is a 75-82 amino acid segment consisting of two highly conserved subregions (Herr et al., 1988). The POU-specific domain contributes to the site-specific and high affinity DNA-binding activity of the POU homeodomain (Ingraham et al., 1990).

Recently, several mammalian genes encoding new members of POU domain proteins have been described. Brn-1,Brn-2,Brn-3, and Tst-1 are genes with overlapping expression in the developing nervous system and in defined regions in adult rat brain ( $\mathrm{He}$ et al., 1989). The SCIP gene product has a POU domain identical to that of Tst-1 and is regulated by CAMP in myelinating glial cells in the central and peripheral nervous systems (Monuki et al., 1989). The Oct-6 gene (Suzuki et al., 1990) encodes an octamer-binding transcriptional activator with a POU domain identical to that encoded by $S C I P / T S t-1$. It is present in embryonic stem cells and in the developing mouse brain; Oct-4 (Schöler et al., 1990a), also referred to as Oct-3 (Okamoto et al., 1990; Rosner et al., 1990), is a transcription factor that might play a role during early mouse development (Rosner et al., 1991). A Drosophila gene (Cf1a), encoding a sequence-specific DNA-binding protein that is highly homologous to the mammalian POU domain proteins required for the expression of the DOPA decarboxylase gene in specific dopaminergic neurons, has been identified Johnson and Hirsch, 1990). Recently it has been shown that in the Drosophila central nervous system Cf1a protein is coexpressed with a structurally distinct POU domain protein referred to as I-POU (Treacy et al., 1991). This protein lacks 2 basic residues in the $\mathrm{N}$-terminus of its homeodomain, and although unable to bind DNA, it does form a stable heterodimeric complex with Cf1a, preventing it from binding DNA and activating transcription. It is likely that I-POU represents a new class POU domain transcription factors with the ability to modulate gene transcription by inhibiting positive POU domain regulators.

Oct-2 (also called OTF-2 and NF-A2) was the first member of POU domain proteins identified as a tissue-specific transcriptional activator. It binds to the octamer motif ATCCAAAT, which is present in the immunoglobulin gene promoters and in the $\mathrm{IgH}$ enhancer and mediates $B$ cell-specific transactivation (Ephrussi et al., 1985; Landolfi et al., 1986; Staudt et al., 1986; Scheidereit et al., 1987; Clerc et al., 1988; LeBowitz et al., 1988; Müller et al., 1988). In contrast, the Oct-1 protein (also called OTF-1, NF-A1, NF-III, and OBP100), which shares the same DNA binding capacity, is found in most cell types and is involved in the activation of ubiquitously expressed genes such as histone $H 2 B$ (Fletcher et al., 1987) and U2-/U6 snRNAs (Mangin et al., 1986; Sive and Roeder, 1986; Carbon et al., 1987). Octamer sequences are also present in a 
variety of other genes (for reviews see Hatzopoulos et al., 1988; Schreiber et al., 1989). Recently, we have identified a family of octamer-binding proteins with different regional distribution in various tissues of mouse and rat (Schöler et al., 1989a), suggesting that the transcriptional activity of genes containing octamer motifs might depend on the presence of tissuespecific transactivators.

Several groups have characterized Oct-2 CDNAs and demonstrated that Oct-2 is a single copy gene (Clerc et al., 1988; Müller et al., 1988; Scheidereit et al., 1988; Staudt et al., 1988). The Oct-2 gene encodes a protein with a relative molecular weight of 60,000 (Scheidereit et al., 1987). This protein has subsequently been renamed Oct-2a (OTF-2a), since evidence for a second lymphoid-specific octamer-binding protein with a relative molecular weight of approximately 75,000 , referred to as Oct-2b, has been presented (Schreiber et al., 1988). We have previously shown that Oct-2a and Oct- $2 b$ are differentially spliced products of the same gene, expressed in different ratios in B cells, brain, kidney, testes, and intestine (Hatzopoulos et al., 1990; Wirth et al., 1991).

Transcriptional activation from a TATA box in front of the $\beta$-globin reporter gene via the octamer motif has been demonstrated by ectopic expression of Oct-2a in HeLa cells (Müller et al., 1988). A combination of mutagenesis and expression analysis also revealed that the POU domain by itself can act as a weak transactivator, but the presence of the $\mathrm{N}$-terminal glutamine-rich domain of the Oct-2a protein is required for full transcriptional activity (Müller-Immerglück et al., 1990). Using a similar approach, Gerster et al. (1990) have mapped two activation domains of Oct-2a: one is a proline-rich region at the very end of C-terminus, and the other, enriched in proline, glutamine and leucine, is located upstream from the POU-specific domain.

In the present study we report the characterization of two novel, alternatively spliced Oct-2 gene products, named Oct-2c and Oct-2d (Mini-Oct). In situ hybridization analysis shows that both transcripts are differentially expressed in the CNS and testis. The functional analysis reveals that Oct-2c functions as a transactivator, whereas Mini-Oct is transcriptionally neutral and could serve to down-regulate the transcriptional effect of the active octamer-binding factors. We speculate that natural products of the Oct-2 gene, differentially expressed in the CNS, possess distinct transactivation and repression capacities and could reflect a fine tuning of gene expression in the developing and adult nervous systems.

\section{Results}

\section{Characterization of cDNA Clones}

We screened $10^{6}$ plaques from a mouse brain cDNA library and identified 12 clones that hybridized to a 618 bp fragment (probe F; Hatzopoulos et al., 1990) covering the entire POU domain of the Oct-2 gene.
These clones belong to three groups, with inserts of $2.3,1.7$, and $1.0 \mathrm{~kb}$. Analysis of these clones showed that the $2.3 \mathrm{~kb}$ and $1.7 \mathrm{~kb}$ cDNAs encoded two new Oct-2 transcripts. The clone with the $1.0 \mathrm{~kb}$ insert was an incomplete cDNA of the Oct-2b transcript, lacking part of the 5 end. The nucleotide and the predicted amino acid sequences of these Ort-2 CDNAs are presented in Figure 1. Previously, we have established the exon-intron organization of a part of the Oct-2 gene. Comparison of the genomic sequences with the newly isclated cDNAs revealed that $2.3 \mathrm{~kb}$ and 1.7 $k b$ cDNAs are new Oct-2 transcripts, generated by differential splicing (see Figure 2).

The DNA sequence of the $2.3 \mathrm{~kb}$ cDNA (referred to as Oct-2c) has an open reading frame, beginning at nucleotide 6 and ending at nucleotide 1360, that encodes a protein of 451 amino acids (Figure 1A). The sequences surrounding the first ATG initiation codon fits well with the consensus sequences for a translation initiation site (Kozak, 1986). The same initiation codon is used in the Oct-2a and Oct-2b transcripts (see Clerc et al., 1988; Scheidereit et al., 1988; Hatzopoulos et al., 1990). In the Oct-2c cDNA there is a deletion of 48 bp upstream of the POU-specific box (exon 3 in Figure 2), as compared with the published murine Oct-2a cDNA sequence. An identical deletion is found in the human Oct-2a transcripts (Clerc et al., 1988) and in murine Oct-2b transcripts (Hatzopoulos et al., 1990) and results from the use of an alternative splice-acceptor site during mRNA splicing. We have previously shown that Oct-2a and Oct-2b differ at their $3^{\prime}$ ends because of an insertion of a 74 bp long exon (exon 10) present in Oct-2b (Hatzopoulos et al., 1990; see also Figure 2). Exon 10 is located in the intron sequences of the Oct-2a transcript and creates a new open reading frame. As a result, in Oct-2b the last 12 amino acids are replaced by 132 new residues from exon 11. The Oct-2c transcript continues as far as exon 9 and includes all the genomic sequences up to exon 11. Because a stop codon is found behind the splice donor site at exon 9, the open reading frame of Oct-2c stops there; consequently, Oct-2c lacks the last 12 amino acids of Oct-2a. With the exception of these differences, Oct-2c is identical to the Oct-2a and Oct$2 \mathrm{~b}$ proteins. Identical domains of these proteins in clude the $\mathrm{N}$-terminal 167 amino acids containing the glutamine-rich domain, the 162 amino acids of the conserved POU domain, and the region of 111 amino acids following the POU homeobox. This latter segment contains the 4 properly spaced leucine residues that are supposed to mediate protein dimerization by the leucine zipper mechanism (Landschultz et al., 1988). Potential polyadenylation signals (AATAAA) are located between nucleotide positions 2348-2353 and 2356-2361, but the clone does not have a poly(A) tract at its end.

The nucleotide sequence of the insert of $1.7 \mathrm{~kb}$ cDNA clones, referred to here as Oct-2d, is shown in Figure $1 \mathrm{~B}$. Oct-2d has a short open reading frame $(232$ amino acids) that starts at position 547 of the CDNA 
and ends at position 1243. The $\mathrm{N}$-terminus of this protein has been assigned to the most 5' AUG codon of the longest open reading frame containing the POU domain. The 474 bp $3^{\prime}$ untranslated region does not include either a consensus polyadenylation signal site or a poly $(A)$ tail. Comparison of the sequences of the Oct-2d cDNA with the genomic sequences indicated that it contains exon 3-4, 5, 6, 7, and 8 (see Figure 2). The additional sequences found upstream of the open reading frame (region $3 \mathrm{a}$ ) and downstream of exon 8 are identical to the adjacent genomic sequences.

The small protein encoded by the $1.7 \mathrm{~kb}$ cDNA, which we call Mini-Oct or Oct-2d, is identical to the other Oct-2 protein variants within the POU domain. Only 26 amino acids precede the POU-specific domain, and they are the same as those in the murine Oct-2a protein. Thus Mini-Oct lacks the N-terminal glutamine-rich region found in the Oct-2a protein. The 44 amino acids following the POU homeodomain are identical in all Oct-2 variants. The protein lacks the C-terminal proline- and serine/threonine-rich regions shown to be important for the high transactivation capability of Oct-2a (Tanaka and Herr, 1990; MüllerImmerglück et al., 1990; Gerster et al., 1990).

\section{Oct 2c and Oct 2d Transcripts Encode Octamer-Binding Proteins}

To determine whether the protein products of the Oct-2c and the Oct-2d genes bind to the octamer motif, we performed electrophoresis mobility shift assays. These assays were performed after in vitro transcription of the corresponding CDNAs and translation in a reticulocyte lysate using a radioactive fragment of the IgH gene enhancer (1W), which contains an octamer motif.

Using the $2.3 \mathrm{~kb}$ cDNA as a template, the sense RNA was translated into a protein that forms a complex with a slightly higher mobility than the BJA-B Oct-2a protein (in Figure $3 A$, lane 8 ). The translation product of the $1.7 \mathrm{~kb}$ cDNA forms a DNA-protein complex migrating faster than the Oct-8-Oct-10 complexes previously described by Schöler et al. (1989a). It should be noted that a faint band with similar mobility was reproducibly detected in $B$ JA-B extracts when large amounts of protein were loaded (Figure 3A, larles 1 and 2). When extracts from mouse brain cortex, isolated at days 0,6 , and 9 after birth, were tested, we found an increase in the intensity of the same band, which implies an enrichment of the Mini-Oct protein in the brain cortex during the early postnatal period (Figure 3B). Taken together, these results indicate that the newly isolated Oct-2c and Oct-2d transcripts encode octamer-binding proteins.

\section{Regional Distribution of Oct-2 Transcripts in the Mouse Nervous System}

Oct-2 transcripts are detected in the nervous system (He et al., 1989; Hatzopoulos et al., 1990) as well as in some glioblastoma cell lines (Staudt et al., 1988). To distinguish the expression patterns of Oct-2d tran- scripts, we used a specific probe (probe P; see Experimental Procedures) made of a 385 bp EcoRI-SstII fragment from the most $5^{\prime}$ part of the region $3 a$. In Northern analysis with RNA isolated from a variety of murine tissues (cerebrum, cerebellum, liver, kidney, heart, intestine, thymus, and testis; data not shown) and cell lines (BJA-B, Ag-8, MOLT-4, EL-4, and primary astrocyte cultures), this cDNA fragment recognized a $2.3 \mathrm{~kb}$ message in Ag-8 cells, a murine B cell line (data not shown). Among the other tissues, only thymus displayed three transcripts of 1.2, 2.3, and $3.1 \mathrm{~kb}$ after prolonged exposure (data not shown). We assume that we failed to obtain detectable signals by Northern analysis because of the very low amount of the transcript in cells other than B lymphocytes.

We applied the more sensitive in situ hybridization method to monitor the expression pattern of Mini-Oct in the mouse CNS. An antisense RNA probe (probe P) was made using the EcoRI-SstII CDNA fragment as a template and applied to follow the Mini-Oct expression, while a sense RNA probe was used to estimate the background signal. To distinguish further the Mini-Oct hybridization pattern from the expression of the other three Oct-2 transcripts, we used probe N, an in vitro synthesized antisense RNA probe derived from a 385 bp Sacl-Nael cDNA fragment (see Hatzopoulos et al., 1990). Probe $N$ contains sequences present in the 3 ' region of Oct-2a, Oct-2b, and Oct-2c, and consequently, the observed hybridization signal should reflect the expression patterns of all these three Oct-2 transcripts, but not Oct-2d.

To examine the expression of Mini-Oct during development of the nervous system, sections of mouse embryos at various developmental stages were hybridized to probe $\mathrm{N}$ and probe $\mathrm{P}$. The results are shown in Figure 4. The earliest hybridization signals were seen at day 10 with both probes and were restricted mainly to the neural tube. In 12 day postcoitum embryos, strong expression was detected for Oct-2a, Oct-2b, or Oct-2c transcripts in the developing diencephalon, mesencephalon, metencephalon, myelencephalon, and spinal ganglia, but not in the telencephalic region. Interestingly, several clusters of strongly expressing cells were detected in the areas where the optic chidsm, mammillary bodies, and neural hypophysis will later appear. These areas also show strong Oct-2 gene expression in the adult brain (Hatzopoulos et al., 1990). The expression in the mesencephalon was confined to the most superficial cell layers of the mesencephalic roof, while in the metencephalon both pontine flexurae and the primordium of cerebellum showed strong hybridization signals (Figure 4B). Transverse sections of embryos at the same stage gave strong positive signals in the intermediate zone (mantle layer), mainly in the ventral part of the developing neural tube (Figure $4 \mathrm{H}$ ). Mini-Oct showed similar expression patterns within the same areas of the developing nervous system, albeit the signal intensity was much weaker (Figures 4C, 4F, and 4l). In contrast, an extremely strong hybridization sig- 


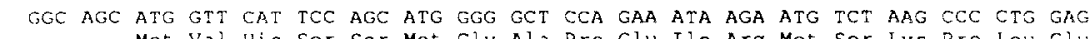
Met Val his Ser Ser Met Gly ala Pro Glu Ile Arg Met ser Lys pro Leu Glu

61 GCC GAG AAG CAA AGT CTG GAC TCC CCG TCA GAG CAC ACA GAC ACC GAA AGA AAT GGA CCC

19 Ala Glu lys Gln ser leu Asp Ser fro Ser Glu His thr Asp Thr Glu arg Asin Giy Pro

121 GAC ATT AAC CAT CAG AAC CCC CAG AAT AAA GCG TCC CCA TTC TCT GTG TCC CCA ACT GGC

29 Asp Ile Asn His Gln Asn Pro Gln Asn Lys Ala Ser Pro phe Ser Val Ser Pro The Gly

181 CCC AGC ACC AAG ATC AAG GCT GAA GAC CCC AGT GGC GAT TCA GCC CCA GCA GCA CCC CCG 59 Pro Ser Thr Lys Ile lys Ala Glu Asp Pro Ser Gly Asp Ser Ala Pro Ala Ala pro pro

241 CCC CCC CAG CCG GCT CAG CCT CAT CTG CCC CAG GCC CAA CTC ATG CTG ACG GGC AGC CAG 9 Pro Pro Gln Pro Ala Gln Pro His Leu Pro Gln Ala Gln Leu Met Leu Thr Giy Ser Gln

301 CTA GCT GGG GAC ATA CAG CAA CTC CTC CAG CTC CAG CAG CTG GTG CTT GTC CCC GGC CAC

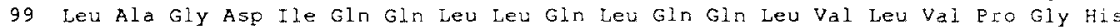

361 CAC ctC CAG CCA CCT gCT CAG tTC CTG CTG CCA CAG GCA CAG CAG agt CAG CCA GgC cte

119 His Leu Gln pro pro Ala Gln phe Leu Leu pro Gln Ala Gln Gin Ser Gln pro Gly Leu

421 CTA CCA ACG CCA AAT CTA TTC CAG CTA CCT CAA CAA ACC CAG GGA GCT CTC CTG ACC TCC

141 Leu Pro Thr Pro Asn Leu phe Gln Leu Pro Gln Gln Thr Gln Gly Ala Leu Leu Thr Ser

481 CAG CCC CGg GCT GGG CTT CCT ACA CAG CCC CCG AAA TGC TTG GAG CCG CCC TCC CAC CCG

159 Gln Pro Arg Ala Gly leu pro Thr Gln pro pro lys Cys leu Glu pro pro ser his pro

$$
\text { POU-SPECIFIC-BOX }
$$

541 GAG GAG CCC AGC GAT CTG GAG GAG CTG GAA CAG TTT GCT CGC ACC TTC AAG CAA CGC CGC

179 Glu Glu pro ser Asp leu Glu Glu leu Glu Gln phe Ala Arg thr phe Lys Gin Arg arg

ATC AAG CTG GGC TmC ACA CAG GGT GAT GTG GGC CTG GCC ATG GGC aAG CTC TAT GGC aAC

Ile Lys Leu Gly the Thr Gin Gly asp val Gly Leu Ala Met Gly hys Leu Tyr Gly Asr

661 GAC TTC AGC CAA ACG ACC ATT TCC CGC TTC GAG GCC CTC AAC CTG AGC ITC AAG AAC ATC

219 Asp phe Ser Gln Thr Thr Ile Ser Arg phe Glu Ala leu Asn Leu Ser Phe Lys Asn Met

721 TGT AAA CTC AAG CCC CTC CTG GAG AAG TGG CTC AAC GAC GCA GAG ACT ATG TCT GTG GAT

719 Cys Lys leu Lys pro leu leu glu lys Trp Leu Asn Asp Ala glu Thr Met Ser val Asp

781 TCA AGC CTA CCC AGC CCA AAC CAC CTG ACC AGC CCC AGC CTG GGT TTC GAC GGG CTG CCO

259 Ser Ser Leu Pro Ser Pro Asn Gin Leu Ser Ser Pro Ser leu Gly phe Asp Gly Leu Pro

$$
\text { POU-HOMEOBOX }
$$

841 CGG CGG $\triangle C A$ CGC AAG $A N C$ ACC $\triangle C C$ ACC $\triangle T C$ GAG ACC AAT GTC CGC TTC GCC TTA GAG AAG 279 Gly Arg|Arg Arg Lys lys Arg thr Ser Ile Glu thr Asn Val Arg phe Ala leu glu lys 901 AGT TTC CTA GCG AAC CAG AAG CCT ACC TCA GAG GAG ATC CTG CTG ATC GCA GAG CAG CTG

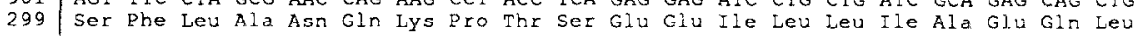

961 CAC ATG GAG AaG GAA GTG ATC CGC GTC TGG TTC TGC AAC CGG CGC CAG AAG GAG AAA CGC 319 His Met Glu Lys Glu Val Ile Arg Val Trp phe Cys Asn Arg Arg Gln Lys glu Lys Arg

1021 ATC AAC CCT TGC AGT GCG GCC CCC ATG CTG CCC AGC CCG GGA AAG CCG ACC AGC TAC AGC 339 Ile Asn Pro Cys Ser Ala Ala pro Met Lel pro Ser pro gly lys pro thr ser tyr ser 1081 CCT CAC CTG GTC ACA CCC CAA GGG CCC GCA CCO ACC TTA CCA ITG TCC CAA GCT TCT AGC 1081 CCT CAC CTG GTC ACA CCC CAN GGG CCC GCA CCG ACC TTA CCA TTG TCC CAA GCT TCT AGC
359 Pro His Leu Val Thr pro Gln Gly Gly Ala Gly Thr Leu Pro Leu Ser Gln Ala Ser Ser

359 Pro His Leu val Thr pro Gln Gly Gly Ala Gly Thr Leu pro leu ser gln Ala Ser Ser
1141 AGT CTG AGC ACA ACA GTT ACT ACC TTA TCC TCA GCT GTG GGG ACG CTC CAT CCC AGC CGG

$\begin{array}{rllll}1141 & \text { AGT CTG AGC ACA ACA GTT ACT ACC TTA TCC TCA GCT GTG GGG ACG CTC CAT CCC AGC CGG } \\ 379 & \text { Ser Leu Sex Thr Thr Val Thr Thr Leu Ser Ser Ala Val Gly Thr Leu His Pro Scr Arg }\end{array}$

1201 ACA GCA GGA GGG GGT GGG GGT GGG GGC GGA GCT GCG CCC CCC CTC AAT TCC ATC CCC TCm

399 Thr Ala Gly Gly Gly Gly Gly Gly Gly Gly Ala Ala Pro Pro Leu Asn Ser Ile Pro Ser

1261 GTC ACT CCC CCA CCC CCG GCC ACC ACC AAC AGC ACA AAC CCG AGC CCT CAA GGC AGC CAC

419 Val Thr Pro Pro pro Pro Ala Thr Thr Asn Ser Thr Asn Pro ser pro gln Gly Ser His

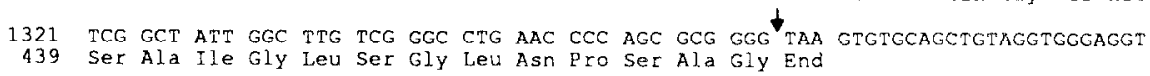

1379 GGGAGGTCTCAGCTGCTCTCAGGGTGGGGAGATGCACCTCAGTTCTGCCATGGGTGCCCCTGCCCCCCCATCCCCCGCT 1458 AACGCCTCTGCTTTGCTCTTGCAGAAGCACAATGGTGGGGTTGAGCTCTGGGCTGAGTCCAGCCOTCATGAGCANCAAC 1537 CCT TTGGCCACTATCCAAGGTGCGTGCTGCCTCATGTCACCCCATTGCCACCAGTCCTGTCCTCTCCTGGGCCTCGAGC 1616 CCACCCTCCCCCATTGCTGCCCCAGCCATGCCATCCCGCCCCCCTGCTCACTGCATTGCTCGCCTCFTCATCCCCATCI 1695 GTCTTCGGGAAAGGTGTGAGGGGTGTTCCTTCACGGGAGTCGGTGGGACAGGTGGGGAGACGGGGTACTCAGGCAGGGT 1774 CACAGAGGCCAAGGTCTCCCTAGCCTGATST TCCAACCTCCAGCTCAGCCTCTCT T TCTCCTCACCAGCCCTGGCCTCT 1853 GGTGGAACCCTGCCCCTTACCAGCC TTGATGGCAGCGGGAACCTGGTGCTGGGGGCAGCCGGTGCGGCCCCAGGGAGTC 1932 CCAGCTTAGTAACCTCGCCTCTCTTCTTGAACCACACCGGTCTGCCGCTGCTCAGTGCCCCACCAGGCGTGGGCCTGGT 2011 CTCAGCGGCGGCTGCAGCCGTAGCAGCATCCATCTCCAGCAAGTCTCCTGGCCTCTCCTCGTCT TCTTCATCCTCATCA 2090 TCCTCCACGTGCAGTGATGTGGCAGCACAGACCCCTGGAGGCCCCGGAGGACCCGAGGCGGGGTCCAASGCTSAGTGAS 2169 AGCCGGCCATGCCTCCCCTCCTACTCCTCTGAATCTCCCGACCTTGGTCCCCTGCCCAAGAGAGGGTAAGGAGGCTGGT 2327 GAAGACGACAAAGCAAAAAAAATAAATAAATAAACAAAAAAAACAAAGAGACCAAATCCCAACCAAAAAGAAAAGAAAAGA 


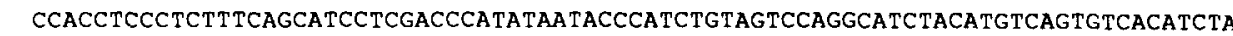
TAGACAGAACCTCAAGCTTCACTCTATGCCTCTGGCCTTGGACAACCTGCTTATTAGTAATCTTAATCTAATAATCCAA 159 TGGGCAGGTGGCGCTGTAGTGATGC TTTCTGTTCAATGGAGGGGAATGTCGGTTCCAGGAGGTTTAAGACGAGCTGAGT 238 TGCCTGTCCACTCAGTCCCAGAGCACGATGCACCATGAACCCTCTCTCCCTAGC TTTGAGCCCACTGAGCCATCAGCAA 317 AGGACACTGGCTGCTCCTTCTGAGAGGTTCGGCCCTCTAAACGAAGGTGAAGAGTAATCGAGAGCACCGCGGTAGGCAG 396 TGGAGTAAAACCTTTAACAGGAATTAGAGATTAGTGTGGGCGACTTGGGCAGGTGAGGCGAGTCTGAAGCAAGCCAGTG 475 CACAACCGTTCCTTAGCCCCATCCAGGTCCTCCATCCCGCATCCCATCCACCTGCCCATCCCCACCAGGCT ATG ACT

553 CGC CCC ACG CTG CCC GAC CCA CAC CTC TCA CAC CCG CAG CCC CCG AAA TGC TTG GAG CCG 3 Arg Pro thr leu pro Asp pro His Leu Ser his pro Gin Pro Pro lys Cys Leu glu pro POU-SPECIFIC-BOX

613 CCC TCC CAC CCG GAG GAG CCC AGC GAT CTG GAG GAG CTG GAA CAG TTT GCT CGC ACC TTC 23 Pro Ser His Pro Glu Glu Pro Ser Asp Leu Glu Glu Leu Glu Gln Phe Ala Arg Thr Phe 673 AAG CAA CGC CGC ATC AAG CTG GGC TTC ACA CAG GGT GAT GTG GGC CTG GCC ATG GGC AAG 43 Lys Gln Arg Arg Ile Lys Leu Gly phe Thr Gln Gly Asp Val Gly Leu Ala Met Gly Lys CTC TAT GGC AAC GAC TTC AGC CAA ACG ACC ATT TCC CGC TTC GAG GCC CTC AAC CTG AGC

63 Leu Tyr Gly Asn Asp Phe Ser Gln Thr Thr Ile Ser Arg Phe Glu Ala Leu Asn Leu Ser

793 TTC AAG AAC ATG TGT AAA CTC AAG CCC CTC CTG GAG AAG TGG CTC AAC GAC GCA GAG ACT 83 Phe Lys Asn Met Cys Lys leu Lys pro leu leu glu Lys trp leu Asn Asp Ala Glu Thr

853 ATG TCT GTG GAT TCA AGC CTA CCC AGC CCA AAC CAG CTG AGC AGC CCC AGC CTG GGT TTC 103 Met Ser Val Asp Ser Ser Leu Pro Ser Pro Asn Gln Leu Ser Ser Pro Ser Leu Gly Phe POU-HOMEOBOX

913 GAC GGG CTG CCG GGg CGG AGA CGC AAG AAG AGG ACC AGC ATC GAG ACG AAT GTC CGC TTC 123 Asp Gly Leu Pro Gly Arg Arg Arg Lys Lys Arg Thr Ser Ile Glu Thr Asn Val Arg Phe 973 GCC TTA GAG AAG AGT TTC CTA GCG AAC CAG AAG CCT ACC TCA GAG GAG ATC CTG CTG ATC 143 Ala Leu Glu Lys Ser phe Leu Ala Asn Gln Lys pro Thr Ser Glu Glu Ile Leu Leu Ile

1033 GCA GAG CAG CTG CAC ATG GAG AAG GAA GTG ATC CGC GTC TGG TTC TGC AAC CGG CGC CAG 163 Ala Glu Gln Leu His Met Glu Lys Glu Val Ile Arg Val Trp phe Cys Asn Arg Arg Gln

1093 AAG GAG AAA CGC ATC AAC CCT TGC AGT GCG GCC CCC ATG CTG CCC AGC CCG GGA AAG CCG 183 Lys Glu Lys Arg Ile Asn Pro Cys Ser Ala Ala Pro Met Leu Pro Ser Pro Gly Lys Pro 1153 ACC AGC TAC AGC CCT CAC CTG GTC ACA CCC CAA GGG GGC GCA GGG ACC TTA CCA TTG TCC

203 Thr ser Tyr ser Pro His Leu val Thr Pro Gln Gly Gly Ala Gly thr Leu pro leu ser

1213 CAA GCT TCT AGC AGT CTG AGC ACA ACA GGT TAG AgGCAGGCTGgGaggGagacCGgGatgacacACAC 223 Gln Ala Ser Ser Ser Leu Ser Thr Thr Gly End

1281 TGCATGGCTACAGCCTGAGGTTCAGCGGTGGCTCTGGGCAGCTGTGGACCTCAAGGCCGAGTCTCTCGGGTGGTACTGG

1360 GCAGACAGAGCAGAGAGCAGCCTCTAGTCAGCTCCACAGTTCCCTGGAAGGCAGCACTCATTGTCCCTTGGCCTCTGTC

1439 AGGTCTTTGCCCTGTGATGGAGCTTGCTCAGTGCATAGAGCTCTGGGGTCCATCTCCAGCCTCAGGATTTCTITAAACA

1518 TTTTATTTGTTTGTTTTTATTTATGAGCTGGGGTTGTTAAGTTGTTTTGTATCATGAGCATGCTGTGCCCAATAGACA

1597 CCAGAAGAGGGCATCAGATCCCCAGGAACTGGAGTTGTTAACAGTTATGAGCTACCATGTGGGTGTTGGGATTCCAAAA

1676 TCCCAGGTCCTCTGGAAGAGCAGCCAATGCTCITGA

Figure 1. Nucleotide Sequence and Predicted Amino Acid Sequence of Murine Oct-2c and Oct-2d

The POU-specific and POU homeobox sequences are boxed. The arrows above the Oct-2c (A) and Oct-2d (B) sequences indicate the location of the exon-intron boundaries. The first arrow does not represent the first exon-intron junction, since the complete structure of the Oct-2 gene is unknown. (A) Two consensus polyadenylation hexamers, AATAAA. are underlined. (B) The additional in-frame AUG initiation codons and the last stop codon before the translational start are underlined.

nal was detected for Mini-Oct in the nasal neuroepithelium of day 16 embryos (Figure $4 \mathrm{~L}$ ), while the expression of Oct-2a, Oct-2b, and Oct-2c was faint in this region (Figure $4 \mathrm{~K}$ ). Thus, the observed differences in the expression patterns reflect not only the different numbers of messages detected by each probe, but also the specific expression of the different Oct-2 transcripts.

To determine the neuroanatomical distribution of Oct-2 messages in adult brain, in situ hybridization was carried out on frontal sections, evenly spaced throughout the brain. It should be emphasized that some brain areas (hippocampus, olfactory bulb, piriform cortex, and granule cell layer of the cerebellum) might give "Nissle-like" artifactual patterns of hybrid- ization, which seems to be correlated with the high density of RNA in these regions. Although these patterns may be more common when double-stranded probes are used (Higgins and Wilson, 1987), the detection of faint signals in these areas was confirmed only after a careful examination of the signal/background ratio in numerous sections. In the olfactory bulb, a strong hybridization signal for Mini-Oct transcripts as well as for the other three Oct-2 transcripts was observed only in the mitral cell layer, whose dendrites synapse with the axons of the bipolar neuronal cells located in the olfactory neuroepithelium of the nasal cavity (Figures 5B and 5C). Similarly, strong labeling was also observed in the olfactory tuberculae and olfactory tract. In the frontopolar cortex, heavy labeling 


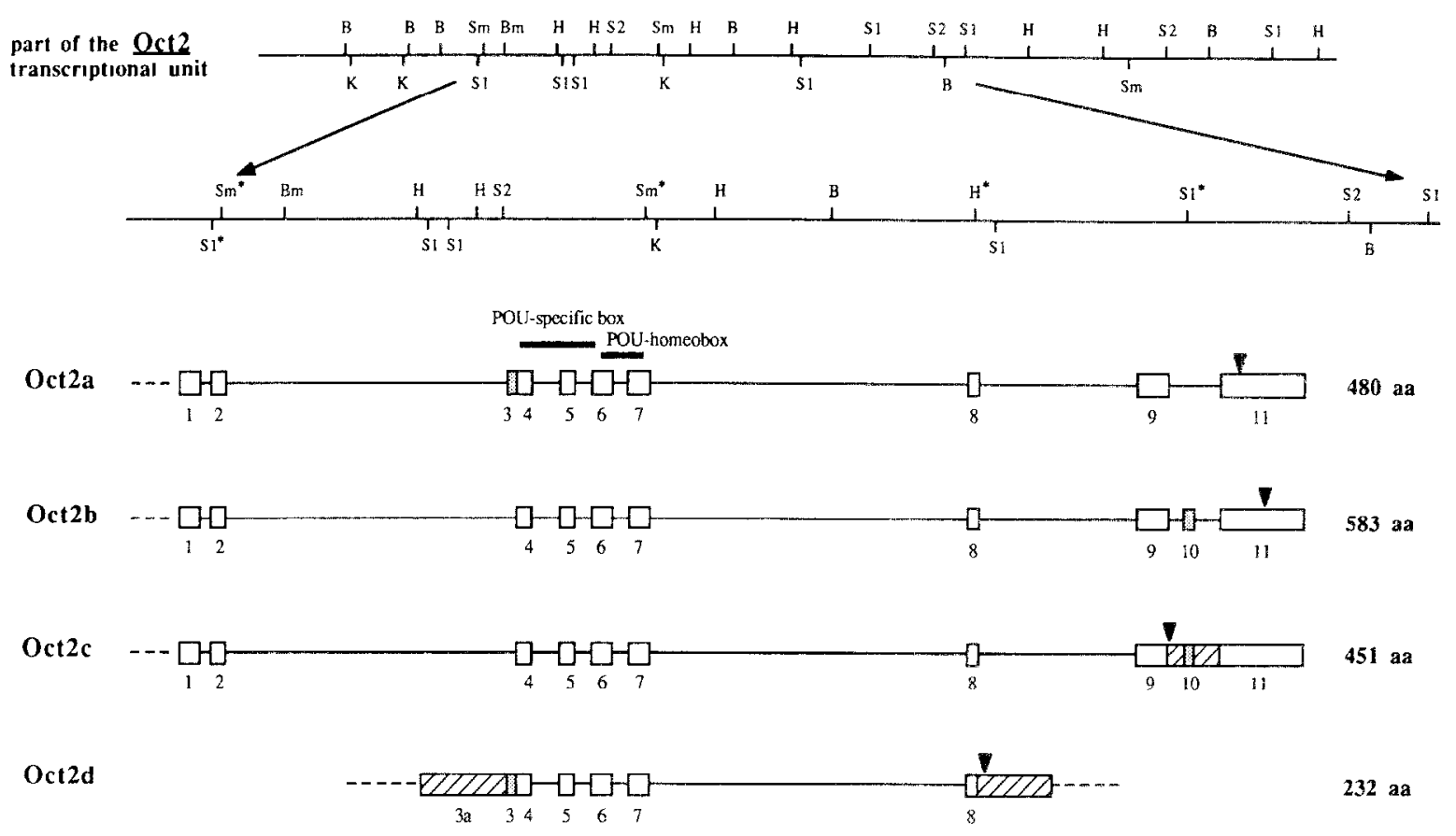

Figure 2. Structure of a Part of the Murine Oct-2 Gene and Alternative Splicing Patierns of Four mRNA Products

The structure is according to Hatzopoulos et al. (1990). The restriction map of $18 \mathrm{~kb}$ of the mouse genome containing a part of the Oct-2 gene is shown on top. The region spanning the Oct-2 gene exons mapped so far is enlarged. Letters mark restriction sites: $B$, Bglli; Bm, BamHI; H, HindIII; K, Kpnl; S1, Sacl; S2, Sacll; Sm, Smal. Restriction sites marked with asterisks are also present in the cDNAs. In the diagram below, boxes represent exons; horizontal lines represent introns; cross-hatched regions indicate the alternatively spliced segments.

was seen with probe $N$ (Figure $5 \mathrm{E}$ ). The signal decreased in the parietal and occipital cortical regions and was restricted primarily to the superficial cortical layers (II-IV). Mini-Oct transcripts were also detected in the frontal cortex (Figure 5F), although at much lower levels. However, no labeling was seen in more caudal cortical areas. Interestingly, the piriform and insular cortices did show accumulation of Oct-2a, Oct-2b, or Oct-2c transcripts, while for Oct-2d, a faint signal was detected only in the piriform cortex (Figure 5I). The hybridization signal for Mini-Oct transcripts in the hippocampal formation was barely detectable (Figure 5L). This contrasts with the high degree of labeling found over the pyramidal cell layers of all regions (CA1-CA4) of Ammon's horn with the common probe $\mathrm{N}$. The granular cell layer of the dentate gyrus and myelinated fiber tracts (such as the corpus callosum, internal capsulae, and optic tracts) were negative with both probes, as compared with the controls. Within the cerebellum, strong accumulation of Oct$2 a$, Oct-2b, and Oct-2c transcripts was observed in the Purkinje cell layer (Figure $5 \mathrm{~N}$ ). In the molecular layer (where stellate and basket cells are scattered) the hybridization signal was of moderate inlensity. In cuntrast, no detectable signal was observed for Mini-Oct transcripts in the cerebellum (Figure 5O).

To summarize, during development, expression of Mini-Oct RNA parallels that of all other Oct-2 transcripts at a much lower level, with the notable excep- tion of an very high message level in the olfactory neuroepithelium. In adult brain, Mini-Oct RNA was prominent in the mitral cell layer of the olfactory bulb and was faintly expressed in the frontopolar and piriform cortices. The message was extremely rare in the hippocampus, and we failed to detect a signal in the insular, somatosensory parietal, and occipital cortices, as well as in the cerebellum.

In situ hybridization analysis with probe $\mathrm{N}$ outlines the expression of Oct-2a, Oct-2b, or Oct-2c transcripts. To gain insight into the possible variation that might be specific for Oct-2c expression, we conducted a study using an RNA probe (probe I; see Experimental Procedures) specific for this transcript. For this purpose, a 75 bp oligonucleotide fragment, corresponding to intron 10 sequences present only in the Oct-2c transcript, was used as a template. In the developing nervous system, the expression of Oct-2c in general parallels the pattern detected with probe $\mathrm{N}$ (data not shown). However, when the hybridization patterns of probes $\mathrm{N}$ and $\mathrm{I}$ in adult brain are compared, several features appear noteworthy. As expected, those areas containing substantial amount of Oct-2C RNA are the mitral cell layer of the olfactory bulb, frontal cortex, piriform cortex, and hippocampus (Figures 6B, 6E, and 6K). The highest level of probe $\mathrm{I}$ binding, specific for Oct-2c, was observed in the insular, somatosensory parietal, and occipital cortices (Figures $6 \mathrm{E}$ and $6 \mathrm{H}$ ). In these cortical areas, the hybrid- 
A

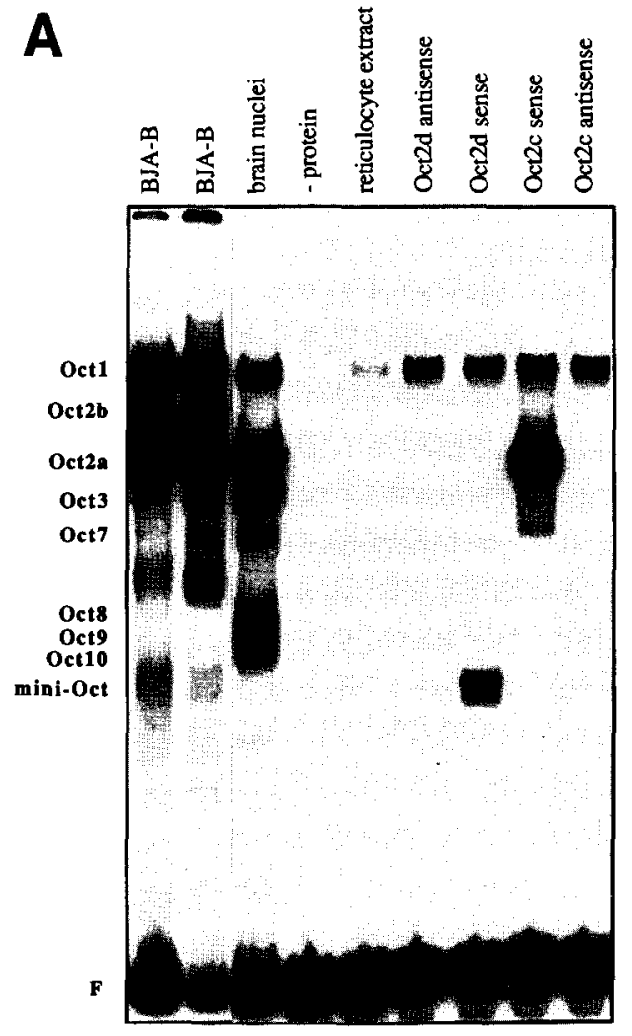

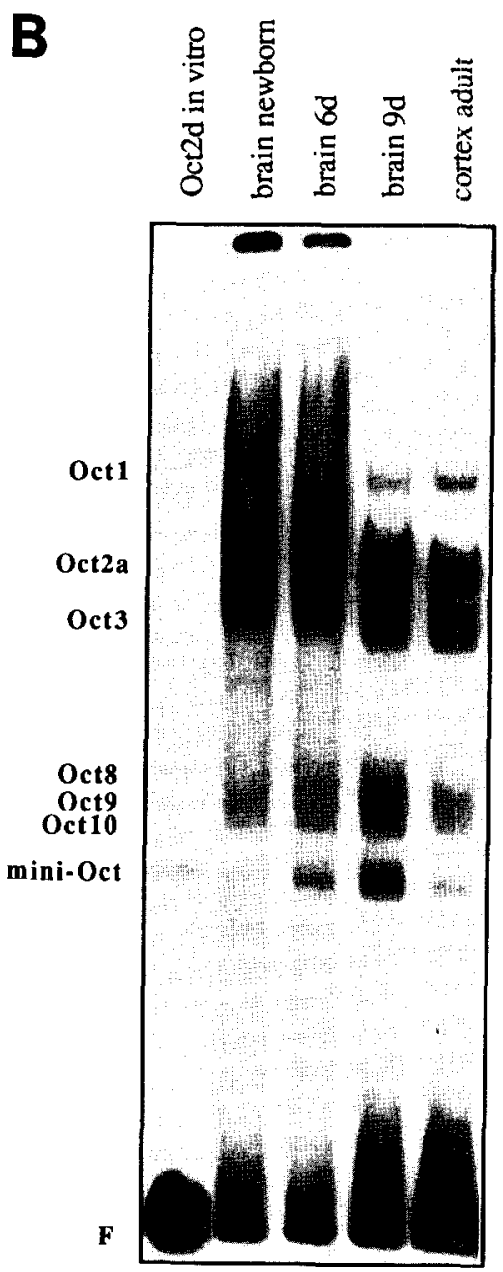

Figure 3. Identification of Octamer DNA-Binding Proteins in a B Cell Line and Various Tissues

(A) The rloned rDNAs encode novel Oct-2 proteins. The phagemids p23 and p5 (lanes 6 and 7) containing the inserts of the $2.3 \mathrm{~kb}$ cDNA and of the $1.7 \mathrm{~kb}$ cDNA were linearized. Sense and antisense RNAs were transcribed in vitro and translated in a rabbit reticulocyte lysate. The in vitro synthesized proteins were analyzed by electrophoretic mobility shift assay with a radioactively labeled oligonucleotide (1W) containing the octamer motif (see Experimental Procedures). The protein complexes described by Schöler et al. (1989a) are indicated. In lane 4 the oligonucleotides were incubated without any extract. BJA-B is a cellular extract from a human mature B cell line. Brain nuclei is extract from nuclei isolated from whole cerebrum of adult mouse as previously described (Stoykova et al., 1979). $F$ marks the position of the unbound oligonucleotides.

(B) Octamer binding activities in extracts from mouse cortex at an early postnatal stage. Radiolabeled 1W was incubated with $8 \mu \mathrm{g}$ of whole cellular extracts of mouse brain cortex, isolated at days 0, 6, 9, or 30 after birth according to procedure of Schöler et al. (1989a), and analyzed by electrophoretic mobility shift assay. Lane 1, bandshift of the in vitro translated product.

ization signal was weak with probe $N$ or negative with probe $\mathrm{P}$, which is specific for Mini-Oct. In the cerebellum, the hybridization signal for Oct-2c was detected mainly on Purkinje cells, and it was of moderate intensity, as compared with the highly accumulated Oct-2C transcripts in the insular, parietal and occipital cortices of the cerebrum (Figure 6N). Earlier we have shown that Oct-2a and Oct-2b are expressed in mouse testis (Hatzopoulos et al., 1990). To determine whether the newly isolated transcripts are also present in this organ, transverse sections through the testis of 20day-old male mice were hybridized to probe $N$ and probe $\mathrm{P}$. High accumulation of Mini-Oct message was observed in primary spermatids (Figures $7 \mathrm{~B}, 7 \mathrm{E}$, and $7 F)$. In contrast, the expression of Oct-2a, Oct-2b, or
Oct-2c was only slightly above the background level (Figures 7C and 7D). Thus, the presence of high levels of Mini-Oct transcripts in primary spermitids and embryonic neuroepithelium and the lack of detectable signals in the cerebellum indicate that the observed patterns reflect quantitative as well as qualitative differences in Mini-Oct expression, as compared with the other Oct-2 transcripts.

\section{Oct-2c and Oct-2d Products Have Different Functional Properties}

Oct-2c and Oct-2d cDNAs were cloned into cytomegalovirus enhancer/promoter expression vectors to examine the functional activity of the Oct-2 gene products (Matthias et al., 1989; see Experimental Proce- 

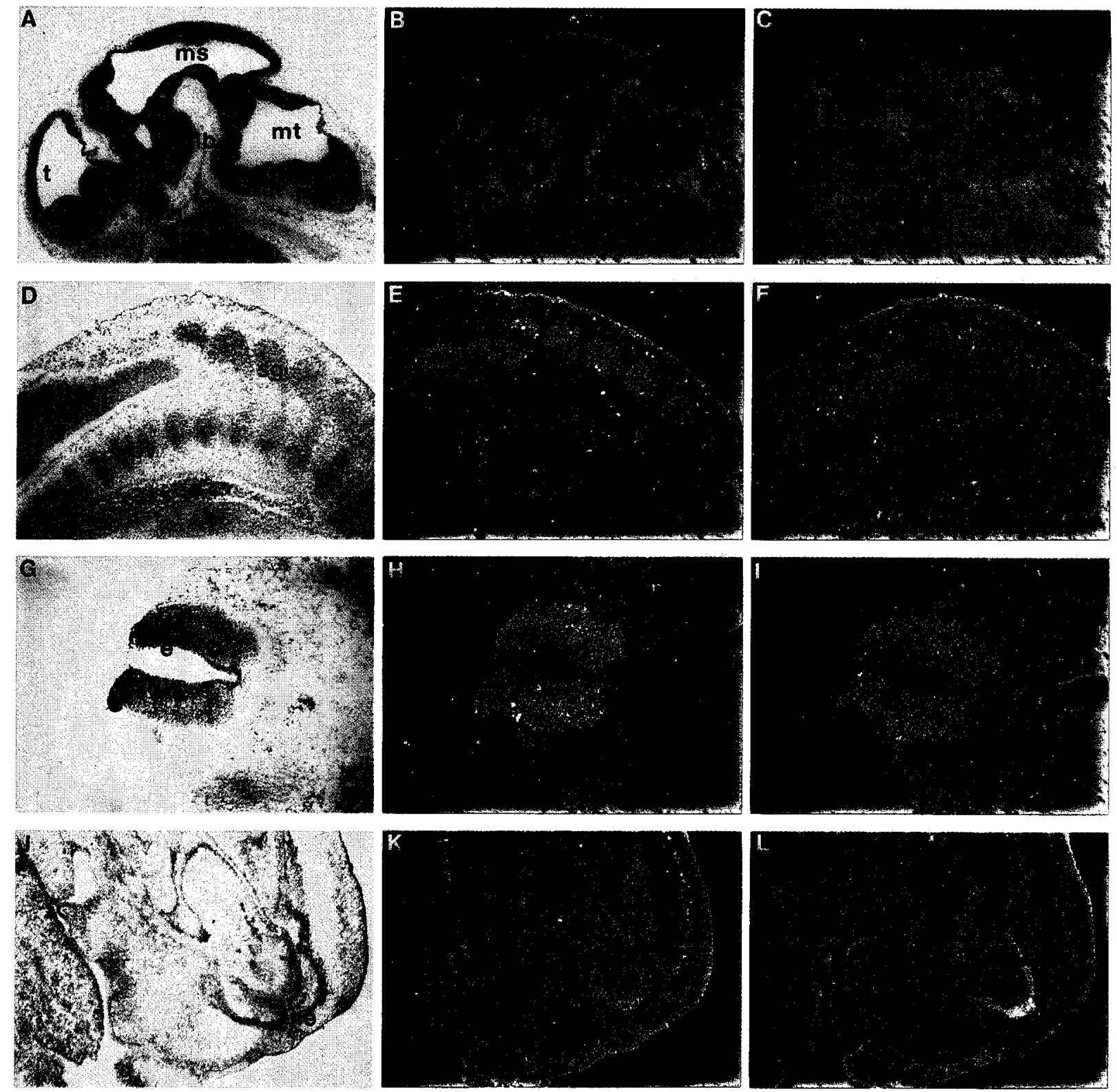

Figure 4. In Situ Hybridization of Oct-2 Transcripts to Embryo Sections

Bright-field ( $A, D, G$, and $J$ ) and dark-field (B, C, E, F, H, I, K, and L) micrographs of adjacent serial sagittal sections hybridized with antisense probe $N(B, E, H$, and $K$ ) or with antisense probe $P(C, F, I$, and $L)$. Note the high expression of Oct-2d in nasal neuroepithelium (L). (A-I) Sections of 12 days postcoitum embryo; (J-L) sections of 16 days postcoitum embryo. (G-I) Transverse sections of neural tube. Abbreviations: $c h$, optic chiasm; d, diencephalon; $e$, ependymal layer; $m$, mantel laver; mb, mammillary body; ms, mesencephalon; $m t$, metencephalon; my, myelencephalon; ne, nasal neuroepithelium; nt, neural tube; pv, prevertebrae; sg, spinal ganglia; t, telencephalon.

dures). The constructs were analyzed individually by transfecting them into HeLa cells together with either normal or mutated OCTA(2) $\beta$-globin target plasmids, based on the OVEC vector (Westin et al., 1987; Müller et al., 1988). The promoter of the OCTA(2) target plasmid contains a single octamer site 5 bp upstream from a TATA box and an SV40 enhancer downstream and is the most permissive test system for Oct-2a activity known so far (Müller-lmmerglück et al., 1990). The transcriptional activity of the Oct-2 protein variants was assessed by measuring the amount of correctly initiated reporter gene RNA by RNAase protection assay.

To test the authenticity (i.e., DNA binding capability) of the Oct-2 proteins generated in HeLa cells, we compared electrophoretic mobility shift assays of wholecell extracts (isolated in parallel from the cells transfected for the transactivation experiments) with those of the in vitro translated corresponding CDNAs and extracts of brain cortex. In initial experiments, expression of the full-length Oct-2d cDNA (1.7 kb cDNA) failed to produce detectable levels of Mini-Oct pro- 

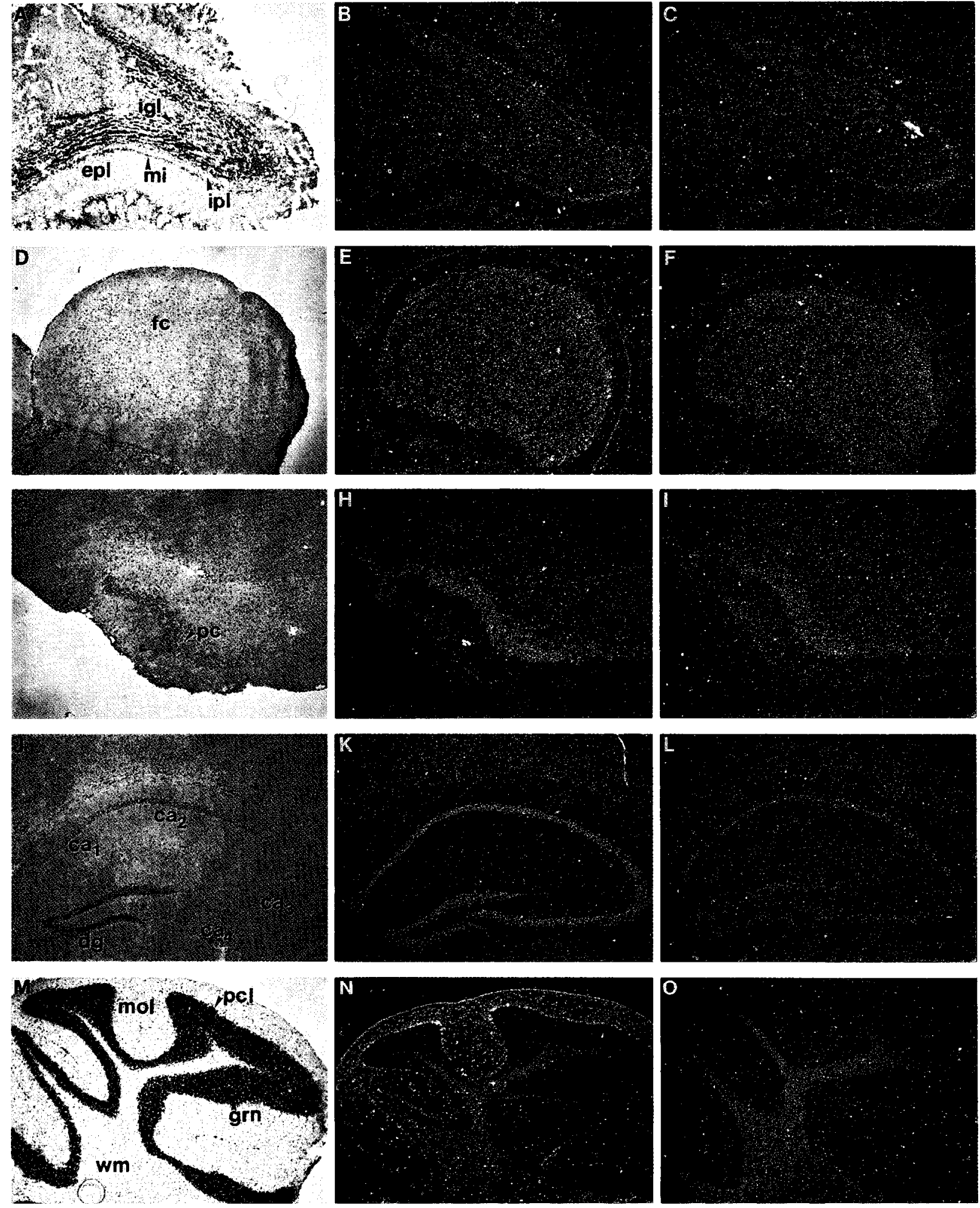

N

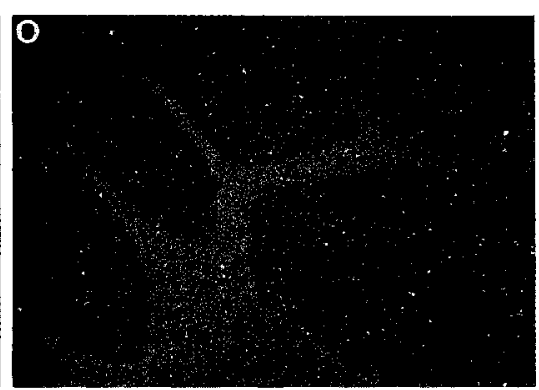

Figure 5. Expression Patterns of Oct-2 Transcripts in Adult Mouse Brain

Adjacent frontal or sagittal $(M, N$, and $O)$ tissue sections of adult mouse brain were hybridized with antisense probe $N(B, E, H, K$, and $\mathrm{N}$ ) or with antisense probe $\mathrm{P}(\mathrm{C}, \mathrm{F}, \mathrm{I}, \mathrm{L}$, and $\mathrm{O})$. Note the extremely low signal in the hippocampus $(\mathrm{L})$ and the lack of a detectable hybridization signal in the cerebellum $(\mathrm{O})$ for Oct-2d. Abreviations: $\mathrm{Ca}_{1}, \mathrm{ca}_{2}, \mathrm{ca}_{3}, \mathrm{Ca}_{4}$, fields in hippocampus; dg, dentate gyrus; epl, external plexiform layer; fc, frontal cortex; grn, granular cell layer; igl, internal granular layer; ipl, internal plexiform layer; mi, mitral cell layer; mol, molecular layer of the cerebellum; pc, piriform cortex; pcl, Purkinje cell layer; wm, white matter. 

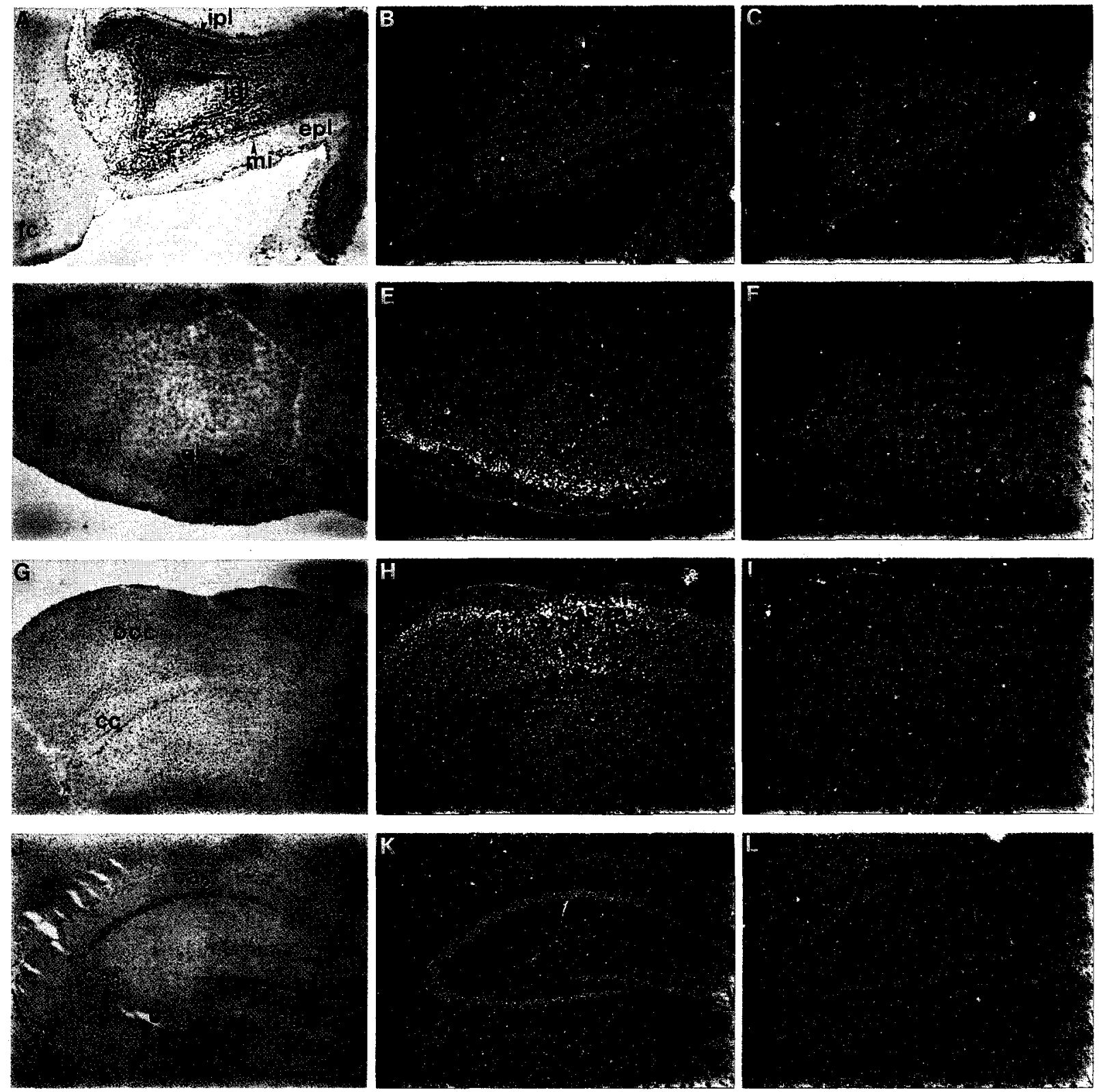

M

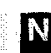

$\mathbf{N}$
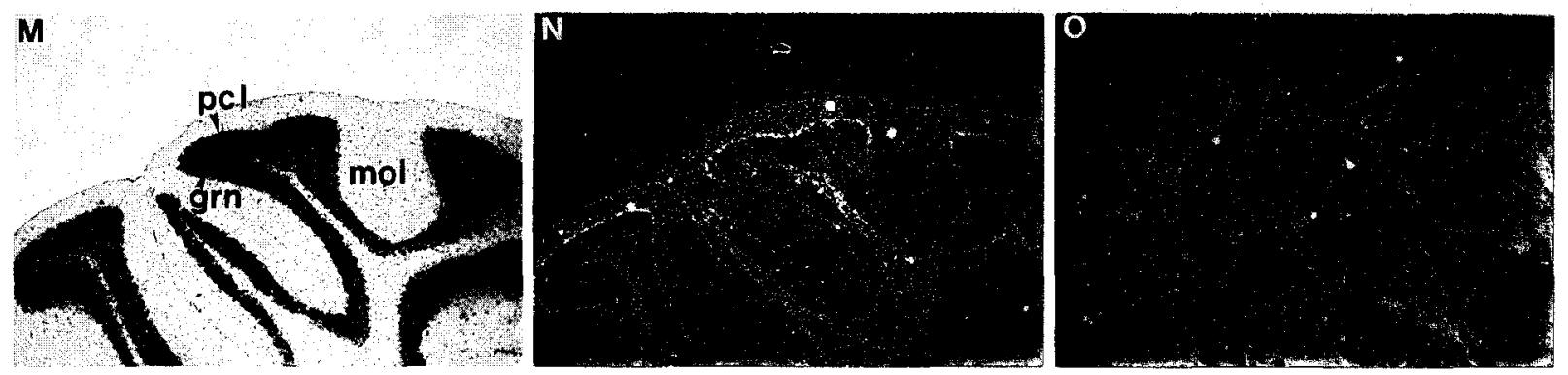

Figure 6. Distribution of Oct-2c Transcripts in Adult Mouse Brain

Frontal and sagittal $(M, N$, and $O$ ) sections (adjacent to those shown in Figure 5) were hybridized with antisense $(B, E, H, K$, and $N)$ or sense $(C, F, I, L$, and $O)$ probe 1 . Note the strong hybridization signal detected for Oct-2c preferentially in the insular (E) and somatosensory (H) cortices. Abreviations: ai, agranular insular cortex; $\mathrm{ca}_{1}, \mathrm{Ca}_{2}, \mathrm{ca}_{3}, \mathrm{ca}_{4}$, fields in hippocampus; $\mathrm{cc}$, corpus callosum; dg, dentate gyrus; epl, external plexiform layer; fc, frontal cortex; gi, granular insular cortex; grn, granular cell layer; igl, internal granular layer; ipl, internal plexiform layer; mi, milral cell layer; mol, molecular layer of the cerebellum; occ, occipital cortex; pc, piriform cortex; pcl, Purkinje cell layer; ss, somatosensory parietal cortex. 

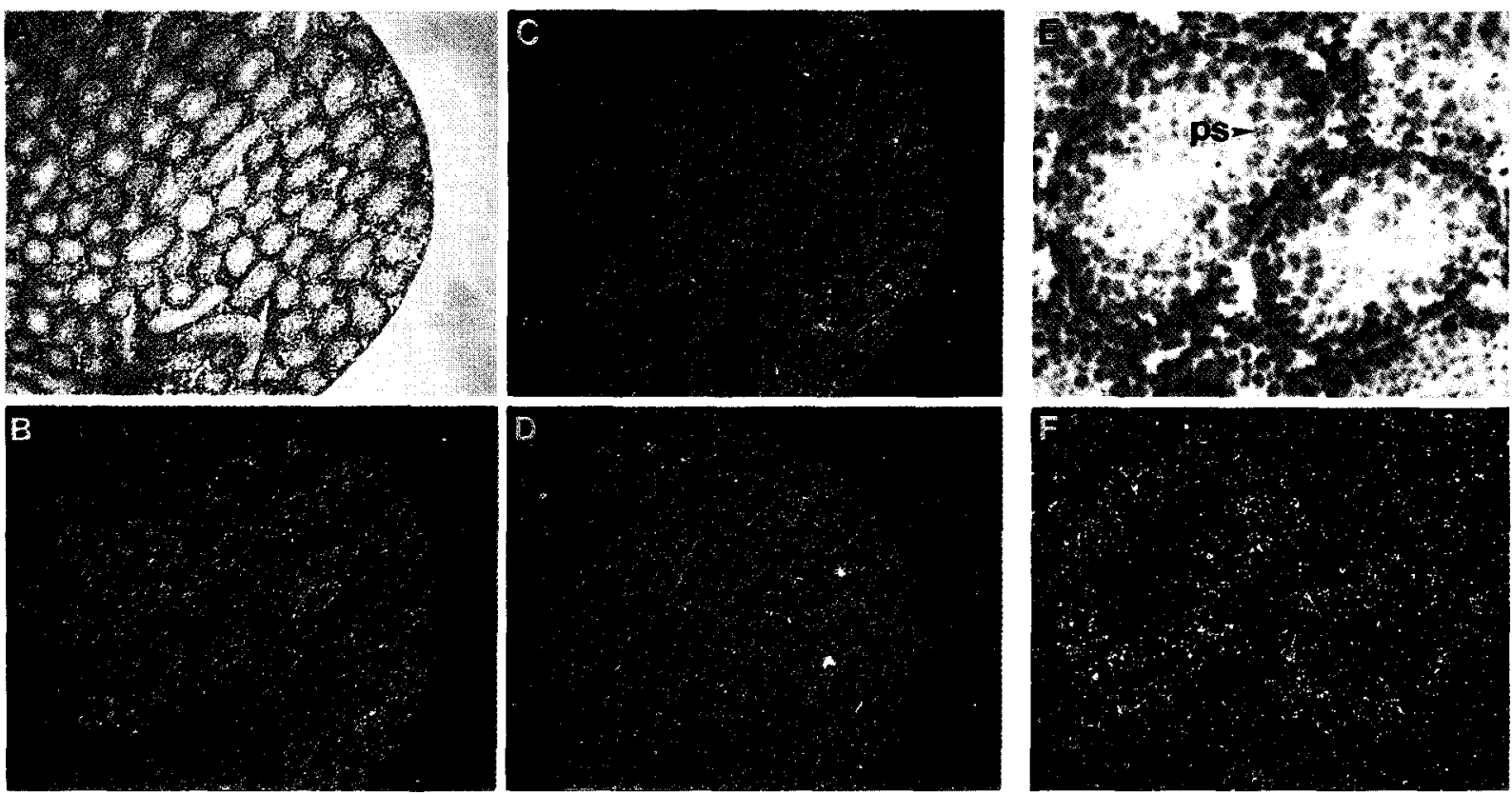

Figure 7. Localization of Oct-2 Transcripts in the Testis

Transverve sections through the testis of a 20-days-old mouse were hybridized with antisense probe $N(C)$, antisense probe $P$ ( $B$ and $F$ ), or sense probe $P(D)$. Note the high accumulation of Oct-2d in primary spermatides (E and F).

tein in HeLa cells. After removal of several in-frame stop codons by truncating the untranslated leader sequence, large amounts of Mini-Oct were synthesized, and the construct pCMV-OCT-2d (see Experimental Procedures) was used for further functional experiments. As shown in Figure 8A, the various Oct-2 proteins generated in HeLa cells shifted the octamercontaining probe $(1 \mathrm{~W})$ to the same position as the corresponding in vitro translated products or the naturally produced protein in brain cortex. It should be noted that although equal amounts of expression plasmids are transfected, the extracts from the Oct$2 d$-transfected cells shifted up to several times more probe than the extracts from cells transfected with Oct-2a or Oct-2c expression plasmids. Despite its large amount, Mini-Oct lacked any detectable transactivation capacity (Figure 8B). However, a very faint band was seen after long exposure, which implies a minimal transactivation capacity for Mini-Oct in this assay (data not shown). As a result of the variable amounts of the individual Oct proteins in transfected cells, it is difficult to compare their transactivation activities directly. Nevertheless, the data presented here show that Oct-2c is a transactivator, while Oct-2d hardly transactivates the OCTA(2) promoter construct, even though it is expressed in greater amounts than Oct-2c.

We have further analyzed whether Mini-Oct possesses modulator activity on genes regulated by different octamer-binding factors. For this purpose, F9 cells that naturally produce Oct-1, Oct-4, Oct-5, and Oct- 6 proteins (Schöler et al., 1989b) were cotransfected with combinations of the target vectors p6WtkCAT or
p6FdtkCAT and either pCMV-Oct-2d or Oct-2d cDNA, cloned into Bluescript (pBS-Oct-2d; Figure 9). The construct p6WtkCAT contains six tandem repeats of the murine IgH gene enhancer fragment ( $1 \mathrm{~W}$ ) located 147 bp upstream from the TATA box of the TK promoter, which acts as an enhancer in F9 cells (Schöler et al., 1989b). When $10 \mu \mathrm{g}$ of target plasmid was cotransfected either with the expression vector (pCMV5; 10 $\mu \mathrm{g}$, Figure 9, lane 1) or with unspecific DNA (pBS/ Oct-2d; $10 \mu \mathrm{g}$, lane 2), no effect was observed on the transcriptional activation by the octamer-binding proteins of F9 cells. Cotransfection of the target construct p6WtkCAT with $5 \mu \mathrm{g}$ of pCMV-Oct-2d resulted in a $50 \%$ decrease of the target's activity (Figure 9, lane 3); cotransfection with 10 or $15 \mu$ of pCMV-Oct-2d resulted in a $73 \%$ or $75 \%$ decrease (lanes 4 and 5 ). No activity was detected when the cotransfection was done with the target plasmid having a mutation in the hexamer 6W (p6FdtkCAT) and pCMV-Oct-2d (Figure 9, lanes 6-8). Similar results for transcriptional inhibition have been obtained in several assays. These data show that Mini-Oct can negatively interfere with transcriptional activation by Oct-4, Oct-5, or Oct- 6 protein in the context of the target construct p6WtkCAT in F9 cells, probably through competative inhibition.

\section{Discussion}

Initially, the Oct-2 gene was thought to be exclusively expressed in lymphoid B cells. However, Oct-2 gene transcripts have been shown to be also present in the developing and adult mammalian CNS (He et al., 1989; Hatzopoulos et al., 1990) and in some glioblastoma 

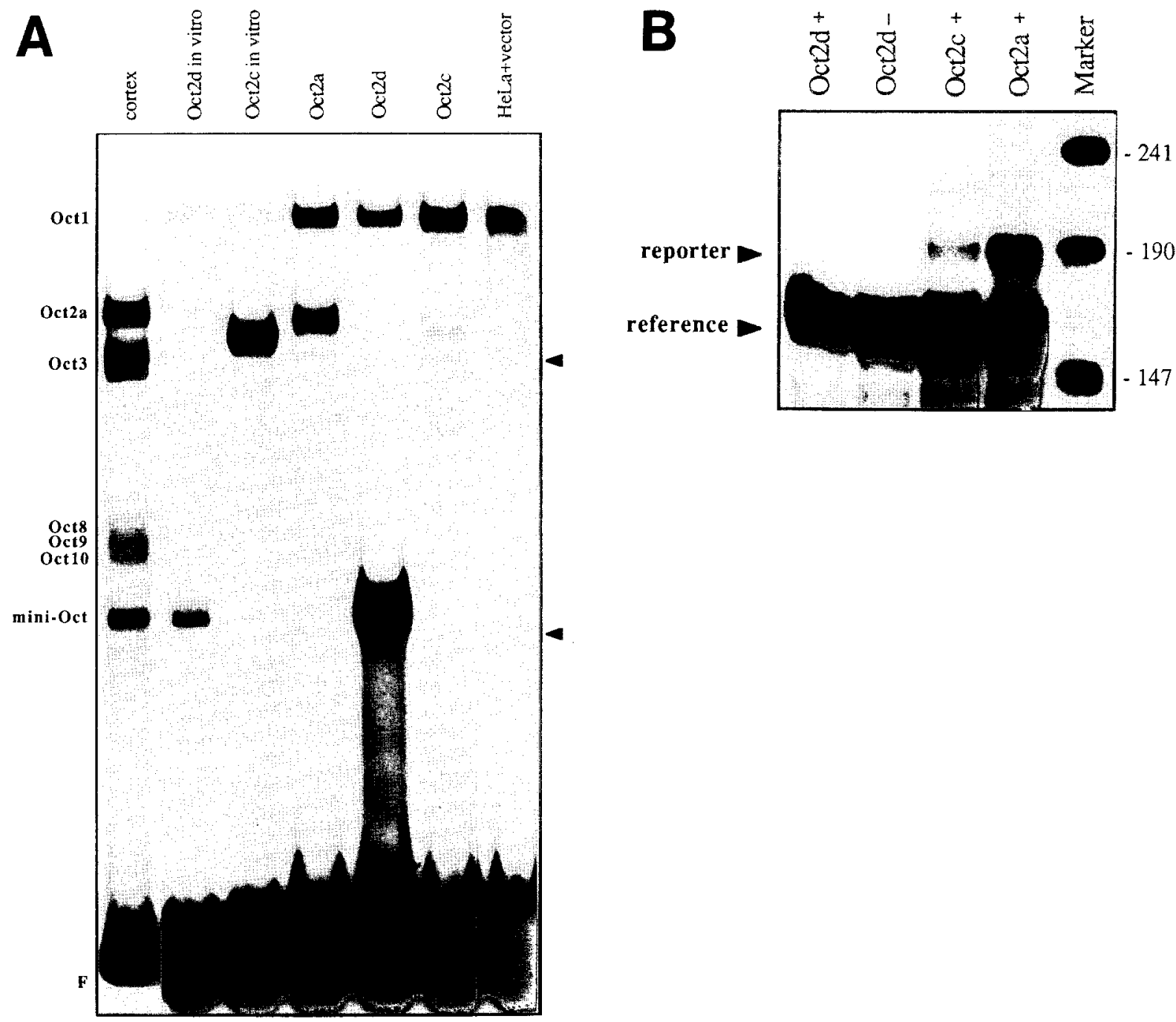

Figure 8. DNA Binding and Transactivation Capacity of Different Oct-2 Proteins

(A) Bandshift experiment with cellular extracts from HeLa cells expressing transfected Oct-2c and Oct-2d cDNAs. Radiolabeled $1 \mathrm{~W}$ oligonucleotides were incubated with cellular extracts prepared from a fraction of the transfected cells with the expression plasmids pCMV-Oct-2a (Müller et al., 1988; lane 4), pCMV-Oct-2d (lane 5), and pSCT-Oct-2c (lane 6). For comparison, the binding of the in vitro transcribed and translated Oct-2d (lane 2), Oct-2c (lane 3), and extract from brain cortex (lane 2) is presented. For each lane, $6 \mu \mathrm{g}$ of protein was loaded. The arrowheads indicate nonspecific binding of HeLa cell extract, transfected with the pCMV5 vector (lane 7 ). (B) Activation of the OCTA(2) promoter by cloned Oct-2c and Oct-2d cDNAs determined by RNAase protection analysis. Expression plasmids carring the Oct-2d (lanes 1 and 2), Oct-2c (lane 3), or Oct-2a (lane 4) cDNA were cotransfected with reference and reporter plasmid containing either a wild-type (lane 1) or a mutated octamer motif (lane 2) as described in Experimental Procedures. The protected bands, corresponding to the mRNAs derived from the reporter plasmid and the reference plasmid, are indicated.

cell lines (Staudt et al., 1988). We have previously reported that two alternatively spliced Oct-2 gene products (Oct-2a and Oct-2b) are present in different ratios in $B$ cells, mouse embryos, and a variety of adult murine tissues, including brain, testis, kidney, and intestine. In this paper we describe the molecular cloning and analysis of two novel products of the murine Oct-2 gene, designated as Mini-Oct (Oct-2d) and Oct2c. We present evidence that these products are generated by alternative splicing and have distinct functional properties and expression patterns in the developing and adult mammalian CNS, as well as in testis.

\section{Genomic Organization of Oct-2c and Mini-Oct}

The Oct-2 transcriptional unit has a complex structure. Our results show that only an $18 \mathrm{~kb}$ section of the gene contains 11 exons, which are alternatively spliced into four transcripts differing in their coding capacities: Oct-2a, Oct-2b, Oct-2c, and Oct-2d (Mini-Oct). The complexity of the Oct-2 gene is also reflected in the great size heterogeneity of the Oct-2 mRNAs reported so far. Using Northern blot analysis, Staudt et al. (1988) described six mRNAs $(7.2,5.8,5.4,3.7,3.1$, and $1.3 \mathrm{~kb})$ present in different amounts in pre-B, B, and plasma cell lines. In another study, at least four different mRNAs of $6.0,3.9,3.3$, and $2.0 \mathrm{~kb}$ have been detected 

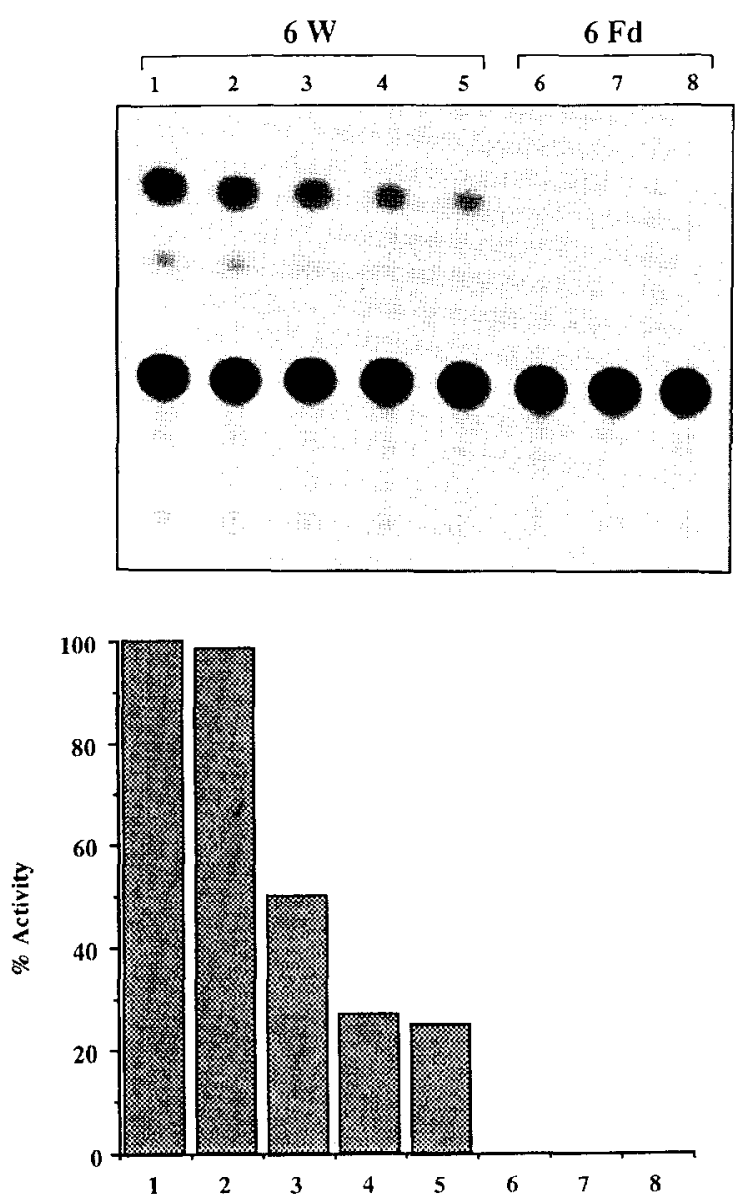

Figure 9. Repression of the 6W Enhancer by Cloned Mini-Oct in 19 Cells

F9 cells were cotransfected with the following combinations of target and expression vectors or nonspecific DNA: lanes 1-5 show cotransfection of the target plasmid p6WtkCAT $(10 \mu \mathrm{g})$ together with pCMV-Oct-2d (5 $\mu \mathrm{g}$, lane 3; $10 \mu \mathrm{g}$, lane 4; $15 \mu \mathrm{g}$, lane 5), the pCMV expression vector $(10 \mu g$, lane 1$)$, or $\mathrm{pBS}$ Oct-2d (Oct-2d cDNA cloned in Bluescript; $10 \mu \mathrm{g}$, lane 2). Lanes 6-8 show the mutated version in the hexamer $6 \mathrm{~W}$, p6FdtkCAT $(10 \mu \mathrm{g})$ together with pCMV-Oct-2d (5 $\mu \mathrm{g}$, lane 6; $10 \mu \mathrm{g}$, lane 7; $15 \mu \mathrm{g}$, lane 8 ). The bottom histogram illustrates results from the corresponding CAT assays. CAT extracts were prepared $48 \mathrm{hr}$ after transfection, and the assay was performed with appropriate amounts of extract according to the internal standard (luciferase; see Experimental Procedures). Schematic presentation of the CAT activity. Controls (columns 1 and 2) were referred to as $100 \%$ and $98 \%$, respectively. Transfections were repeated several times and yielded similar results for repression of the transcription.

in lymphoid cells of the B lineage (Müller et al., 1988). Furthermore, each of the specific probes for the CDNA clones, isolated by Clerc et al. (1988), recognized different sets of two messages with sizes either lower than $2.3 \mathrm{~kb}$ or higher than $4.4 \mathrm{~kb}$, respectively. In our Northern analysis of eight murine tissues and various cell lines with a probe specific for the $5^{\prime}$ untranslated region of the newly identified sequences of Mini-Oct, we found clear hybridization with mRNA species of approximately $2.3 \mathrm{~kb}$ only in murine B cells. After longer exposure, two additional bands of 1.2 and 3.1 $\mathrm{kb}$ appeared. The fact that a specific probe for MiniOct transcript detects mRNA populations with a larger size than expected most probably indicates a partial truncation of the $5^{\prime}$ end of the isolated $1.7 \mathrm{~kb}$ cDNA. rurther examination, including primer extension assay, would help to clarify this issue. Although the nature of the missing sequences is not known, it seems unlikely that they could affect the predicted protein product, since the initiation codon assigned to position 547 of the $1.7 \mathrm{~kb}$ cDNA is the only in frame with the POU domain AUG that is not followed by stop codons (Figure 1B). Because of the very low abundance of the Oct-2 messages in tissues other than B cells and the limited sensitivity of Northern analysis, we were not able to detect Oct-2 transcripts in the brain. Therefore the possibility remains that a MiniOct probe recognizes other, still unidentified Oct-2 transcripts. This issue will be resolved only when the complete array of Oct-2 transcripts is isolated.

Our results show that different products of the same gene possess distinct functional capacities as a result of alternative splicing. Among the nucleotide sequences of Oct-2 cDNAs published so far-murine Oct-2a (Hatzopoulos et al., 1990), human Oct-2a (Scheidereit et al., 1988; Clerc et al., 1988; Müller et al., 1988), murine Oct-2b (Hatzopoulos et al., 1990), and the Oct-2c and Oct-2d transcripts - two types of splicing pattern affecting the protein-coding region outside the POU domain can be seen. High flexibility is observed in the splicing pattern of the small exon 3-4 (only $48 \mathrm{bp}$ ) (see Figure 2). It is present in the murine $B$ cell Oct-2a transcript, but resides in the intron sequence of the human Oct-2a transcript, as well as in murine Oct-2b and Oct-2c. Interestingly, in Oct-2d the same sequence is included in a new exon and is preceded by a large untranslated region. The AUGs that precede the main AUG are followed by several inframe stop codons, which impair the translation efficiency of Oct-2d in vivo, as shown in our functional assay. However, this mRNA was translated efficiently in vitro (Figure $3 \mathrm{~A}$ ). The alternative splicing of exon 3 results in a small deletion of 16 amino acids after the glutamine-rich region of the Oct-2 protein in the corresponding variants. Functional analysis has failed to assign any significance to these internal residues (Gerster et al., 1990).

Alternative splicing in the 3 ' region of the Oct-2 gene. transcripts is responsible for the generation of the Oct-2a, Oct-2b, and Oct-2c RNAs, which give rise to three different proteins with distinct carboxyl ends. Oct-2c lacks the last 12 amino acids present in Oct-2a. These amino acids are also absent from Oct-2b, but they have been replaced by 132 new residues, which create a C-terminus with considerably homology to the corresponding region of the Oct-1 protein.

Recently, Wirth et al. (1991) have described six functional isoforms of Oct-2 cDNA from murine B cells, generated by an alternative splicing mechanism. One of their clones is identical to the Oct- $2 b$ cDNA reported by us previously (Hatzopoulos et al., 1990). 
Three others encode proteins that shift the probe in a bandshift assay to a position similar to that held by the Oct-2a complex present in BJA-B nuclear extract. This supports the notion that the previous designation of lymphocyte Oct-2a does not describe a single protein, but rather a family of similarly sized protein variants (Scheidereit et al., 198?; Müller et al., 1988; Schreiber et al., 1988). However Oct-2c cDNA and Mini-Oct cDNA presented in this work have not yet been described.

\section{Oct-2 Gene Products with Different Function Capacities Have Distinct Expression \\ Patterns in the CNS}

Using cotransfection assays, several groups have recently delineated those Oct- 2 domains that are required for transcriptional activation of a target promoter in HeLa cells (Müller-Immerglück et al., 1990; Gerster et al., 1990; Tanaka and Herr, 1990). At least two domains contribute to transcriptional activation by Oct-2. One of these domains is located at the $\mathrm{N}$-terminus and contains clusters of amino acids, extremely rich in proline, leucine, and glutamine residues. Removal of this region markedly reduces the transcriptional activity. Another activation domain is located in the C-terminal serine-, threonine-, and proline-rich region. Removal of the leucine zipper region along with the segment enriched in threonine/serine residues does not abolish transactivation capacity, showing that the putative leucine zipper of Oct-2a is not essential for the transcriptional activation (MüllerImmerglück et al., 1990). The Oct-1 protein has a highly homologous $\mathrm{N}$-terminal and a rather divergent C-terminal region, when comparerd with Oct- 2 . Recently, it has been reported that although the Oct-1 $\mathrm{N}$-terminus can functionally replace the Oct-2 N-terminus, it fails to activate $\beta$-globin transcription because of its inactive $\mathrm{C}$-terminal region (Tanaka and Herr, 1990). The sequences most critical for Oct-2a transactivation capability appear to be localized within the last 18 amino acids at the C-terminus of the protein (Gerster et al., 1990). As shown here, Oct-2c, like Oct-2b (Hatzopoulos et al., 1990), is lacking the last 12 amino acids at its C-terminus. Although further work will be necessary to chararterize quantitatively the transcriptional activity of the different $O c t-2 c$ gene products, it may be expected that these Oct- 2 variants would be weak transactivators as compared with the B cell Oct-2a protein. Recently, Dent et al. (1991) have reported on differences between the $B$ cell and the neuronal forms of Oct- 2 in their binding specificity to naturally occurring octamer sequences and functional activity. The neuronal form of Oct- 2 is a cell type-specific, octamer-binding protein present in C1300 neuroblastoma cells and ND7 cells (immortalized ganglionic neurons). Like Oct-2c, neuronal Oct-2 has mohility in a bandshift gel similar to that of $B$ cell Oct-2a, but inhibits octamer-mediated gene expression. Its functional activity cannot be compared directly with that of Oct-2c because the transactivation capacities are tested in the context of different target promoters. The relationship between the octamerbinding proteins of the immune and nervous systems is an open question (Schreiber et al., 1990). Nevertheless, it seems reasonable to suggest that the Oct-2c CDNA, which was isolated from a brain library, may encode a the nervous system counterpart of lymphocyte Oct-2a. Further study is required to define the extent of such a relation.

The octamer motif acts as a proximal promotor element in Hela cells after ectopic expression of Oct-2a (Müller-Immerglück et al., 1990) or Oct-4 (Schöler et al., 1990b). The Mini-Oct protein is lacking both the $\mathrm{N}$ - and C-terminal fuctional domains, and as shown here, it has no detectable transactivation activity with the same promoter construct when expressed in Hela cells. A delineation of the activating domains of the Oct-2a protein revealed that the POU domain by itself acts as a weak transactivator with the OCTA(2) promoter construct. This capacity is assigned to an activation domain within a short stretch of the amino acids overlapping the $\mathrm{N}$-terminal end of the POU-specific domain (Müller-Immerglück et al., 1990; Gerster et al., 1990). It is tempting to speculate that the amino acids located upstream and/or downstream of the POU domain in Mini-Oct might have a role in supressing the activity of this POU-specific activating domain.

Our results revealed that Mini-Oct can repress the signal generated by endogenous octamer factors in F9 cells on a target containing multimerized octamer sequences. The repression is incomplete but significant. Preliminary results from a competition experiment in HeLa cells between Mini-Oct and Oct-2a for DNA-binding of the octamer motif suggest that MiniOct can also repress transcriptional activation by Oct$2 a$ in the context of OCTA(2) promotor.

It has been recently reported that the octamer motif mediates transcriptional repression of herpes simplex immediate early gene in $\mathrm{C} 100$ neuroblastoma cells and it is assumed that a neuron-specific form of Oct-2 with mobility similar to that of the B cell Oct- 2 protein is responsible for the observed inhibitory effect (Kemp et al., 1990; Dent et al., 1991). In these studies, Mini-Oct binding activity has not been detected, probably because of differences in the expression patterns of octamer-binding proteins in cells of norma! nerve tissue and transformed cell lines of neural origin. As recently demonstrated by Schreiber et al. (1990), astrocytes (but not neuroblastoma or glioblastoma cell lines) contain a wider spectrum of octamerbinding proteins. The present work demonstrates the existence of an octamer-binding factor with repressor activity in normal brain tissue. Genes encoding POU domain transcription factors (except for the Oct3/4 gene) exhibit distinct temporal and spatial expression patterns in the nervous system, with wide expression in the neural tube and subsequent restriction to specific areas of adult brain. It has been suggested, therefore, that they may play a role in the differentiation of specific neural phenotyes (for review see Rosenfeld, 
1991). For example, the expression of the $B r n-1$ and $B r n-2$ genes (layers II-IV) and of the Tst-1/SCIP/Oct-6 genes (layers IV-VI) in the cerebrum is correlated with all stages of establishment of cortical lamination, while the $B r n-3$ transcripts accumulate only in the neural crest-derived sensory ganglion cells (He et al., 1989). In this work we present evidence that the complexity of the expression of the Oct-2 gene in the CNS increases by the mechanism of alternative splicing of its pre-mRNA. Oct-2 gene transcription starts early in the developing nervous system (day 10 postcoitum). Later, various transcripts generally colocalize in the neural tube and in parts of the hindbrain, midbrain, and diencephalon, but are absent from the telencephalon. In most regions of adult brain, their expression patterns are overlapping, but at different levels. The primary difference is the great accumulation of MiniOct transcripts in developing nasal neuroepithelium and the lack of this message in hippocampus and cerebellum of mature brain. The nasal neuroepithelium is the only area in the adult mammalian CNS where growth and differentiation of sensory neurons continue throughout life (Graziadei and Monti-Graziadei, 1978), implying a probable role for Mini-Oct in the proliferative processes in this part of the olfactory system. This possibility is consistent with the Oct- 1 and Oct-2 factors activating both transcription and DNA replication in vitro, and as for Oct-1, an intact POU domain suffices for such a stimulation (Verrijzer et al., 1990). A possible role in DNA replication has been outlined for other octamer-binding proteins. Monuki et al. (1989) reported that the SCIP/Tst-1 gene (which is the rat analog for Oct-6) is transiently expressed in Schwann cells in the proliferative phase preceding myelination. Furthermore, microinjection of antisense Oct-4 oligonucleotides into fertilized oocytes results in a loss of Oct-4 mRNA, which in turn leads to inhibition of DNA synthesis and arrest of the embryo at the 1 cell stage (Rosner et al., 1991).

None of the individual expression patterns of genes encoding POU domain proteins documented so far correspond to any functional system (He et al., 1989). We find it intriguing that different Oct-2 transcripts are detected in topographically connected parts of the olfactory system-from nasal neuroepithelium, through mitral cells in bulbus olfactorius and olfactory tract, to primary olfactory cortical areas (frontal and piriform cortices) and regions of higher order cognition (hippocampus). It is of interest to note that in mature brain, Oct-2 transcripts accumulate in regions that have been shown to be associated with synaptic plasticity. The plasticity in the piriform cortex and hippocampus is related to olfactory learning and to storage of new information, respectively (Haberly and Bower, 1989; Thompson, 1986). The only effective output from the cerebellum is formed by the axons of Purkinje cells, which are also involved in motor plasticity and some kind of conditioning.

Taken together, the data suggest the possibility that Oct-2 protein variants might be involved in the control of neural differentiation and/or plasticity in the adult brain. Our results reveal that distinct alternatively spliced Oct-2 gene products with different functional capacities colocalize with other POU domain proteins. For example, the $B r n-1$ and $B r n-2$ genes are expressed in the cortical layers of the cerebrum and Purkinje cells together with Oct-2a, Oct-2b, or Oct-2c transcripts. Mini-Oct transcripts are detected only in the frontopolar cortex of the cerebrum and are absent from Purkinje cells. Evidence has recently been presented that the POU domain permits protein-protein interactions that may modulate the function of the POU domain transcription factors. In solution, Oct-1 and Oct-2 are monomers and bind cooperatively to two adjacent octamer- and heptamer-binding sites of natural promoters, increasing transcriptional activation (Poellinger et al., 1989). Recombinant Oct-2derived proteins, containing only the POU domain (thus similar to Mini-Oct), are fully active for cooperative binding to adjacent binding sites (LeBowitz et al., 1989). As shown in this work, Mini-Oct fails to transactivate, and it may be expected that this Oct-2 variant would modulate by protein-protein interactions the functional activity of other POU domain transcription factors.

In this study we have shown by in situ hybridization differential expression of two Oct-2 gene products with distinct functional properties in nerve tissue and in testis. Although the transcripts colocalize in most cases, quantitative as well qualitative differences in their expression patterns are detected in the developing nervous system and adult brain. It seems reasonable to suggest that different combinations of octamer-binding proteins, including the multiple Oct-2 variants observed in this study, each with their distinct transactivatior/repressor activity, act together to fine tune gene expression in the nervous system.

\section{Experimental Procedures}

\section{Isolation and Sequencing of cDNAs}

Approximately $10^{6}$ recombinant phage of a brain CDNA library made from 10-day-old mice in the $\lambda Z A$ APII expression vector (kindly provided by Toomas Neumann) were plated and transferred to Hybond N (Amersham) nylon filters. After denaturation, the filters were UV cross-linked and prehybridized at $60^{\circ} \mathrm{C}$ in $7 \times$ SSC, $5 \times$ Denhardt's solution, $0.5 \%$ SDS, $0.1 \mathrm{mg} / \mathrm{ml}$ denatured salmon sperm DNA. The hybridization was performed under the same conditions, containing $10^{6} \mathrm{cpm} / \mathrm{ml}$ random-primed, ${ }^{32} \mathrm{P}$-labeled $628 \mathrm{bp}$ cDNA fragment isolated from a $\lambda \mathrm{gt} 11$ clone of mR2, which spans the entire Oct-2 POU domain (described by Hatzopoulos et al. [1990]). The filters were washed 2 times in $2 x$ SSC, $0.1 \%$ SDS at room temperature and 2 times at $37^{\circ} \mathrm{C}$. The positive phage were plaque purified, and the DNA was isolated according to standard procedures (Sambrook et al., 1989). The isolated cDNA clones were $2.3 \mathrm{~kb}$ and $1.7 \mathrm{~kb}$ in size, and their corresponding transcripts were named Oct-2c and Oct-2d. The inserts of the CDNAs were excised by helper phage (Stratagene, San Diego, CA) to obtain Bluescript II SK recombinant phagemids (designated p23 for the $2.3 \mathrm{~kb}$ cDNA and p5 for the $1.7 \mathrm{~kb}$ CDNA) and used for sequencing and in vitro transcription assays. After subcloning of appropriate restriction fragments into $\mathrm{M} 13$ vectors, sequencing was performed by the dideoxy chain termination method (Sanger et al., 1977) using both deaza dGTP and dITP nucleotides (Sequenase kit from USB). 


\section{Subcloning \\ Probes for the Expression Analysis}

A 385 bp EcoRI-SstII cDNA fragment from the untranslated 5 end of Oct-2d was subcloned in Bluescript (plasmid pP1) and used as a specific probe for Northern analysis. The same plasmid was linearized and used to synthesize antisense or sense RNA probes for the in situ histochemistry. To obtain an appropriate probe to follow the distribution of OCt-2c, a synthetic template was made. Buth strands of a 75 bp oligonucleotide fragment of the $2.3 \mathrm{~kb} c D N A$, corresponding to the nucleotides between positions 1685 and 1759 in Figure $1 \mathrm{~A}$, were synthesized (BioSearch 8700 DNA synthesizer). For cloning, the two single strands were heated to $95^{\circ} \mathrm{C}$ and cooled to room temperature for annealing. The double strands were separated from single strands on a $10 \%$ polyacrylamide gel, cut out, and electroeluted in TE buffer (10 mM Tris-HCl [pH 8], $1 \mathrm{mM}$ EDTA [pH 8]). Subsequently, the oligonucleotides were phosphorylated (polynucleotide kinase; Boehringer Mannheim) and cloned into Bluescript vector. This plasmid ( $\mathrm{pl}$ ) was linearized and used to produce antisense and sense RNA probes by in vitro transcription.

\section{Plasmids for Transient Expression of Oct-2 Proteins}

The expression plasmid for Oct-2a (pCMV-Oct2a) has been described by Müller et al. (1988). To obtain the expression plasmid for Oct-2c (pSCT-Oct 2c), the phagemid p23 was linearized by cutting at its BamHI site, treated with Klenow fragment of DNA polymerase, and digested with Sall; The insert was cloned into Sall and Pvull sites of the cytomegalovirus enhancer/promoter expression vector $\mathrm{PSCT}$, kindly provided by $\mathrm{S}$. Rusconi. To optimize the initiation signal for Oct-2d transcript, the whole $1.7 \mathrm{~kb}$ insert was excised from the phagemid $\mathrm{p} 5$ by digestion with Sall and Pstl, and the untranslated leader sequence was removed by cutting with ApaLI (position 472 in Oct-2d; Figure 1B). After filling in the $5^{\prime}$ overhangs with Klenow fragment and cutting with Clal, the $1.2 \mathrm{~kb}$ fragment was cloned into filled Bglll and Clal sites of the cytomegalovirus enhancer/promoler expression vector described by Andersson et al. (1989) and kindly provided by $M$. Stinski. This construct was named pCMV5-Oct-2d.

\section{Preparation of Nuclear Extracts and Electrophoretic Mobility Shift Assay}

Nuclear extracts were prepared as described earlier (Hatzopoulos et al., 1990). The microextraction procedure for preparation of whole-cell extracts and the conditions for binding and electrophoresis were as described by Schöler et al. (1989a).

\section{In Vitro Transcription and Translation}

Before in vitro transcription, the phagemids containing the cDNAs inserts were linearized. The plasmid p23 (for Oct-2c) was cut with BamHI or Sall to obtain sense or antisense RNA using T7 and T3 RNA polymerases (Promega). The plasmid p5 (for Oct2d) was linearized with Sall or BamHI to obtain sense or antisense RNA with T3 or T7 RNA polymerases, respectively. The reaction conditions were as described by Hatzopoulos et al. (1990). The RNA was translated in a rabbit reticulocyte lysate following the manufacturer's specifications (BRL). One-sixth of the translation mixture was used for the electrophoretic mobility shift assay as described above.

\section{In Situ Hybridization}

In situ hybridization was performed according to Hogan et al. (1986), as modified by Dony and Gruss (1987), and has previously been described in detail (Hatzopoulos et al., 1990). To examine the expression of Oct-2d versus that of Oct-2a, Oct-2b, and Oct$2 c$, groups of three adjacent $8 \mu \mathrm{m}$ cryostate sections of mouse embryos $(10,12,16$ days postcoitum), aduit brain, or testis were hybridized with antisense probe $N$, antisense probe $P$, and sense probe $P$. I he plasmid pN (see Hatzopoulos et al., 1990) was cut with BamHI, and T3 RNA polymerase was used to generate the antisense RNA (probe N). The plasmid pP1 was linearized by BamHI or Sall, and antisense or sense RNA (probe P) was transcribed by $T 3$ or T7 RNA polymerases, respectively. The distribution of Oct-2c was examined by hybridizing the sections with antisense or sense probe l, produced by transcription of the linearized plasmid pl. Radioactive RNA probes with specific activities of $5 \times 10^{5}$ to $8 \times 10^{5} \mathrm{cpm} / \mu$ were prepared using $0.1 \mathrm{mCi}$ of [ ${ }^{35}$ S] ITP and $0.1 \mathrm{mCi}$ of [ ${ }^{35}$ S]C.TP (Amersham) as described by the manufacturer (Promega). Probe $N$ and probe $P$ were subjected to limited alkaline hydrolysis (Cox et al., 1984). All probes were diluted to a specific activity of $5 \times 10^{4} \mathrm{cpm} / \mu \mathrm{l}$ in hybridization buffer before application to the sections. The conditions for hybridization, washes, and dipping in photographic emulsion were as previously described (Hatzopoulos et al., 1990). Sections were exposed for 2 (embryo and testis) or 3 (brain) weeks, developed, and stained with Giemsa (embryo and testis) or $0.5 \%$ of Toluidine blue (brain). Photomicrographs were taken using a Leitz Labovert microscope.

\section{Cell Lines and Cotransfection Analysis}

HeL. cells and $F 9$ cells were grown and transiently cotransfected by the $\mathrm{CaPO}_{4}$ method as desribed by Schöler et al. (1989a) DNA for transfection was purified by using Qiagen columns (DIAGEN). The $\beta$-globin reporter plasmid $(8 \mu \mathrm{g})$, internal OVEC reference ( $1 \mu \mathrm{g}$; Westin et al., 1987), expression vector $(4 \mathrm{ng})$, and Bluescript DNA $(7 \mu \mathrm{g})$ were transfected into Hela cells on 100 $\mathrm{mm}$ dishes. After $48 \mathrm{hr}$, the cells were harvested. One-sixth of the cells were used for the microextraction procedure of the cellular proteins, and the rest for the extraction of cytoplasmic RNA. Twenty micrograms of this RNA was hybridized to a radioactive complementary RNA probe, synthesized on linearized plasmid SPBTS, described by Westin et al. (1987). Hybridization products were analyzed by RNAase protection assay according to Picard and Schaffner (1985). F9 cells were cotransfected with $10 \mu \mathrm{g}$ of either the target construct p6WtkCAT or p6FdtkCAT, which has a mutation in the hexamer $6 \mathrm{~W}$ (Schöler et al., 1989b) together with either the expression plasmid pCMV5-Oct2d or Oct-2d cDNA cloned in Bluescript vector ( $\mathrm{pBS}-\mathrm{Oct} 2 \mathrm{~d}$ ). After 48 $\mathrm{hr}$, the cells were harvested and chloramphenicol acetyltransferase (CAT) assays were performed as described by Schöler et al. (1990b).

In each transfection, $3 \mu \mathrm{g}$ of pSV2 LUC was cotransfected as an internal control, and the appropriate amount of extract was used according to the luciferase assay.

\section{Acknowledgments}

We are grateful to W. Schaffner and E. Schreiber for providing us with the expression plasmid pCMV-Oct-2a and the reporter plasmids OCTA(2)+ and OCTA(2)-, as well as to $S$. Rusconi for supplying the $\mathrm{PSCT}$ expression vector. We thank T. Neumann for providing the mouse brain cDNA library and protein extracts from postnatal brain cortex. We are indebted to B. Föhring for help with the computer analysis, R. Altschäffel for photographic work, and H.P. Geithe for the synthesis of oligonucleotides. We also thank $H$. Schöler for his encouraging advice on transactivation experiments and constant interest in the work. Furthermore, we would like thank V. Subramanian, U. Deutsch, $M$. and Y. Goulding, and A. Püschel for valuable comments on the manuscript. A. S. S. and A. K. H. were recipients of postdoctoral fellowships from the Alexander von Humboldt Foundation and the Max-Planck Society. S. S. is supported by the Human Frontier Science Programme. This work was supported by the MaxPlanck Society and by the Bundesministerium für Forschung und Technologie (BMFT).

The costs of publication of this article were defrayed in part by the payment of page charges. This article must therefore be hereby marked "advertisement" in accordance with 18 USC Section 1734 solely to indicate this fact.

Received August 19, 1991; revised December 30, 1991.

\section{References}

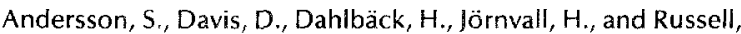
D. W. (1989). Cloning, structure, and expression of the mitochondrial cytochrome $P-450$ sterol 26-hydroxylase, a bile acid biosynthetic enzyme. J. Biol. Chem. 264, 8222-8228. 
Aviv, H., and Leder, P. (1972). Purification of biologically active globin messenger RNA by chromatography on oligothymidylic acid-cellulose. Proc. Natl. Acad. Sci. USA 69, 1409-1414.

Bodner, M., Castrillo, J.-L., Theill, L. E., Deerinck, T., Ellisman, M., and Karin, M. (1988). The pituitary-specific transcription factor GHF-1 is a homeobox-containing protein. Cell 55, 505-518.

Carbon, P., Murgo, S., Ebel, J.-P., Krol, A., Tebb, G., and Mattaj, I. W. (1987). A common octamer motif binding protein is involved in the transcription of U6 snRNA by RNA polymerase III and U2 snRNA by polymerase II. Cell $51,71-79$.

Chirgwin, J. M., Przybyla, A. E., MacDonald, R. J., and Rutter, W. I. (1979). Isolation of biologically active ribonucleic acid from sources enriched in ribonuclease. Biochemistry 18, 5294-5299.

Clerc, R. G., Corcoran, L. M., LeBowitz, J. H., Baltimore, D., and Sharp, P. A. (1988). The B-cell-specific Oct-2 protein contains POU box and homeo box-type domains. Genes Dev. 2, 1570-1581.

Cox, K., De Leon, D., Angerer, L., and Angerer, R. (1984). Detection of mRNAs in sea urchin embryos by in situ hybridization using asymmetric RNA probes. Dev. Biol. 101, 485-502.

Dent, C. L., Lillycrop, K. A., Estridge, J. K., Thomas, N. S. B., and Latchman, D. S. (1991). The B-cell and neuronal forms of the octamer-binding protein Oct-2 differ in DNA-binding specificity and functional activity. Mol. Cell. Biol. 11, 3925-3930.

Dony, C., and Gruss, P. (1987). Specific expression of the Hox 1.3 homeo box gene in murine embryonic structures originating from or induced by mesoderm. EMBO J. 6, 2965-2975.

Ephrussi, A., Church, G. M., Tonegawa, S., and Gilbert, W. (1985) B-lineage-specific interactions of an immunoglobulin enhancer with cellular factors in vivo. Science 227, 134-140.

Fletcher, C., Heintz, N., and Roeder, R. G. (1987). Purification and characterization of OTF-1, a transcription factor regulating cell cycle expression of a human $\mathrm{H} 2 \mathrm{~b}$ gene. Cell 51, 773-781.

Gehring, W. J. (1987). Homeo-boxes in the study of development. Science 236, 1245-1252.

Gerster, T., Balmaceda, C.-C., and Roeder, R. G. (1990). The cell type-specific octamer transcription factor OTF-2 has two domains required for the activation of transcription. EMBO ।. 9 1635-1643.

Graziadei, P. P., and Monti-Graziadei, G. A. (1978). The olfactory system: a model for the study of neurogenesis and axon regeneration in mammals. In Neural Plasticity, C. W. Cotmann, ed. (New York: Raven Press), pp. 131-153.

Haberly, L. B., and Bower, J. M. (1989). Olfactory cortex: model circuit for study of associative memory. Trends Neurosci. 12 258-259.

Hatzopoulos, A. K., Schlokat, U., and Gruss, P. (1988). Enhancers and other cis-acting regulatory sequences. In Transcription and Splicing. F. Frontiers in Molecular Biology, B. D. Hames and D. M. Glover, eds. (Washington D.C.: IRL press), pp. 43-96.

Hatzopoulos, A. K., Stoykova, A. S., Erselius, J. R., Goulding, M. Neumann, T., and Gruss, P. (1990). Structure and expression of the mouse Oct2a and Oct $2 b$, two differentially spliced products of the same gene. Development 109, 349-362.

He, X., Treacy, M. N., Simmons, D. M., Ingraham, H. A., Swanson, L. W., and Rosenfeld, M. G. (1989). Expression of a large family of POU-domain regulatory genes in mammalian brain development. Nature 340, 35-42.

Herr, W., Sturm, R. A., Clerc, R. G., Corcoran, L. M., Baltimore, D., Sharp, P. A., Ingraham, H. A., Rosenfeld, M. G., Finney, M. Ruvkin, G., and Horvitz, H. R. (1988). The POU domain: a large conserved region in the mammalian pit-1, oct-1, oct-2, and Caenorhabditis elegans unc-86 gene products. Genes Dev. 2, 1513-1516.

Higgins, G., and Wilson, M. C. (1987). In Situ Hybridization. Applications to Neurobiology, K. L. Valentino, J. H. Eberwine, and J. D. Barchas, eds., pp. 146-162.

Hogan, B., Constantini, F., and Lacy, E. (1986). Localization of gene transcripts in embryo sections. In situ hybridization with RNA probes. In Manipulating the Mouse Embyo: A Laboratory
Manual (Cold Spring Harbor, New York: Cold Spring Harbor Laboratory), pp. 228-242.

Ingraham, H. A., Chen, R., Mangalam, H. J., Elsholtz, H. P., Flynn, S. E., Lin, C. R., Simmons, D. M., Swanson, L., and Rosenfeld, M. C. (1988). A tissue-specific transcription factor containing a homeodomain specifies a pituitary phenotype. Cell 55, 519-529. Ingraham, H. A., Flynn, S. E., Voss, J. W., Albert, V. R., Kapiloff, M. S. Wilson, L., and Rosenfeld, M. G. (1990). The POU-specific domain of Pit-1 is essential for sequence-specific, high affinity DNA binding and DNA-dependent Pit-1-Pit-1 interactions. Cell 61, 1021-1033.

Johnson, W. A., and Hirsch, J. (1990). Binding of a Drosophila POU-domain protein to a sequence element regulating gene expression in specific dopaminergic neurones. Nature 343, 467470 .

Kemp, L. M., Dent, C. L., and Latchman, D. S. (1990). Octamer motif mediates transcriptional repression of HSV immediateearly genes and octamer-containing cellular promoters in neuronal cells. Neuron 4, 215-222.

Ko, H.-S., Fast, P., McBride, W., and Staudt, L. M. (1988). A human protein specific for the immunoglobulin octamer DNA motif contains a functional homcobox domain. Cell 55, 135-144.

Kozak, M. (1986). Point mutations define a sequence flanking the AUC initiator codon that modulates translation by eukaryotic ribosomes. Cell 44, 283-292.

Landolfi, N. F., Capra, J. D., and Tucker, P. W. (1986). Interaction of cell-type-specific nuclear proteins with immunoglobulin $\mathrm{VH}$ promoter region sequences. Nature 323, 548-551.

Landschultz, W. H., Johnson, P. F., and McKnight, S. L. (1988) The leucine zipper: a hypothetical structure common to a new class of DNA binding proteins. Science 240, 1759-1764.

Laughon, A., and Scott, M. P. (1984). Sequence of a Drosophila segmentation gene: protein structure homology with DNAbinding proteins. Nature $370,25-31$.

LeBowitz, I. H., Kobayashi, T., Staudt, L., Baltimore, D., and Sharp, P. A. (1988). Octamer-binding proteins from B or HeLa cells stimulate transcription from the immunoglobulin heavychain promoter in vitro. Genes Dev. 2, 1227-1237.

LeBowitz, J. H., Clerc, R. G., Brenowitz, M., and Sharp, P. A. (1989). The Oct-2 protein binds cooperatively to adjacent octamer sites. Genes Dev. 3, 1625-1638.

Lenardo, M. J., Staudt L., Robbins, P., Kuang, A., Mulligan, R. C., and Baltimore, D. (1989). Repression of the IgH enhancer in teratocarcinoma cells associated with a novel octamer factor. Science $243,544-546$.

Mangin, M., Ares, M., Jr., and Weiner, A. M. (1986). Human U/2 small nuclear RNA genes contain an upstream enhancer. EMBO J. 5, 987-995.

Matthias, P., Müller-Immerglück, M. M., Schreiber, E., Rusconi, S., and Schaffner, W. (1989). Eukaryotic expression vectors for the analysis of mutant proteins. Nucl. Acids Res. 17, 6418.

McGinnis, W., Levine, M. S., Hafen, E., Kuroiwa, A., and Gehring, W. J. (1984). A conserved DNA sequence in homeotic genes of the Drosophila Antennapedia and bithorax complexes. Nature 308, 428-433.

Monuki, E. S., Weinmaster, G., Kuhn, R., and Lemke, G. (1989). SCIP: a glial POU domain gene regulated by cyclic AMP. Neuron 4, 783-793.

Müller, M. M., Ruppert, S., Schaffner, W., and Matthias, P. (1988). A cloned octamer transcription factor stimulates Iranscription from lymphoid-specific promoters in non-B cells. Nature 336 544-551.

Müller-Immerglück, M. M., Schaffner, W., and Matthias, P. (1990). Transcription factor Oct-2A contains functionally redundant activating domains and works selectively from a promote but not from a remote enhancer position in non-lymphoid (HeLa) cells. EMBO J. 9, 1625-1634.

Okamoto, K., Okazawa, H., Okuda, A., Sakai, M., Muramatsu, M., and Hamada, H. (1990). A novel octamer binding transcrip- 
tion factor is differentially expressed in mouse embryonic cells. Cell 60, 461-472.

Picard, D., and Schaffner, W. (1985). Cell-type preference of immunoglobulin and gene promoters. EMBO f. 4, 2831-2838.

Poellinger, L., Yosa, B. K., and Roeder, R. G. (1989). Functional cooperativity between protein molecules bound to two distinct sequence elements of the immunoglobulin heavy-chain promoter. Nature 337, 573-576.

Rosenfeld, M. G. (1991). POU-domain transcription factors: pouer-ful developmental regulators. Genes Dev. 5, 897-907.

Rosner, M. H., Vigano, A. M., Ozato, K., Timmons, P. M., Poirier, F., Rigby, P. W. J., and Staudt, L. M. (1990). A POU-domain transcription factor in early stem cells and germ cells of the mammalian embryo. Nature 345, 687-693.

Rosner, M. H., De Santo, R. J., Arnheiter, H., and Staudt, L. M. (1991). Oct-3 is a maternal factor required for the first mouse embryonic division. Cell 64, 1103-1110.

Sambrook, J., Fritsch, E. F., and Maniatis, T. (1989). Molecular Cloning: A Laboratory Manual. Second Edition (Cold Spring Harbor, New York: Cold Spring Harbor Laboratory).

Sanger, M. P., Nicklen, S., and Coulsen, A. R. (1977). DNA sequencing with chain termination inhibitors. Proc. Natl. Acad. Sci. USA 74, 5463-5467.

Santoro, G., Mermod, N., Andrew, P. C., and Tjian, R. (1988). A family of human CCAAT-box-binding proteins active in transcription and DNA replication: cloning and expression of multiple cDNAs. Nature 334, 2218-2?24.

Scheidereit, C., Heguy, A., and Roeder, R. G. (1987). Identification and purification of a human lymphoid-specific octamer binding protein (OTF-2) that activates transcription of an immunoglobulin promoter in vitro. Cell 51, 783-793.

Scheidereit, C., Cromlish, J. A., Gerster, T., Kawakami, K., Balmaceda, C.-G., Currie, A. R., and Roeder, R. G. (1988). A human lymphoid-specific transcription factor that activates immunoglobulin genes is a homeobox protein. Nature 336, 551-557.

Schöler, H. R., Hatzopoulos, A. K., Balling, R., Suzuki, N., and Gruss, P. (1989a). A family of octamer-specific proteins present during mouse embryogenesis: evidence for germline-specific expression of an Oct-factor. EMBO J. 8, 2543-2550.

Schöler, H. R., Balling, R., Hatzopoulos, A. K., Suzuki, N., and Gruss, P. (1989b). Octamer binding proteins confer transcriptional activity in early mouse embryogenesis. EMBO J. 8, 25512557.

Schöler, H. R., Ruppert, S., Suzuki, N., Chowdhury, K., and Gruss, P. (1990a). New type of POU domain in germ line-specific protein Oct-4. Nature 344, 435-439.

Schöler, H. R., Dressler, G. R., Balling, R., Rohdewohld, H., and Gruss, P. (1990b). Oct-4: a germline-specific transcription factor mapping to the mouse t-complex. EMBO J. 9, 2185-2195.

Schreiber, E., Matthias, P., Müller-lmmerglück, M. M. and Schaffner, W. (1988). Identification of a novel lymphoid specific octamer binding protein (OIF-2B) by proteolytic clipping bandshift assay (PCBA). EMBO J. 7, 4221-4229.

Schreiber, E., Müller-Immerglück, M. M., Schaffner, W., and Matthias, P. (1989). Octamer transcription factors mediate B-cell specific expression of immunoglobulin heavy chain genes. In Tissue Specific Gene Expression, R. Renkawitz, ed. (Weinheim: Verlag Chemie), pp. 33-54.

Schreiber, E., Harshmyn, K., Kemler, l, Schaffner, W., and Fontana, A. (1990). Astrocytes and glioblastoma cells express novel octamer-DNA binding proteins distinct from the ubiquitous Oct-1 and B-cell type Oct-2 protein. Nucl. Acids Res. $18,5495-$ 5503.

Scott, M. P., and Weiner, A. J. (1984). Structural relationships among genes that control development: sequence homology between the Antennapedia, Ultrabithorax, and fushi tarazu loci of Drosophila. Proc. Natl. Acad. Sci. USA 81, 4115-4119.

Singh, H., Sen, R., Baltimore, D., and Sharp, P. A. (1986). A nuclear factor that binds to a conserved sequence motif in transcrip- tional control elements of immunoglobulin genes. Nature 319 , 154-158.

Sive, H. L., and Roeder, R. G. (1986). Interaction of a common factor with conserved promoter and enhancer sequences in histone $\mathrm{H} 2 \mathrm{~B}$ immunoglobulin, and $\mathrm{U} 2$ small (sn) RNA genes. Proc. Natl. Acad. Sci. USA 83, 6382-6386.

Staudt, L. M., Singh, H., Sen, R., Wirth, T., Sharp, P. A., and Baltimore, D. (1986). A lymphoid-specific protein binding to the octamer motif of immunoglobulin genes. Nature 323, 640-643. Staudt, L. M., Clerc, R. G., Singh, H., LeBowitz, I. H., Sharp, P. A., and Baltimore, D. (1988). Cloning of a lymphoid-specific CDNA encoding a protein binding the regulatory octamer DNA motif. Science $247,577-580$.

Stoykova, A. S., Dabeva, M. D., Dimova, R. N., and Hadjiolov, A. A. (1979). Ribosomal RNA precursors in neuronal and glial rat brain nuclei. ). Neurochem. 33, 931-937.

Sturm, R. A., Das, G., and Herr, W. (1988). The ubiquitous octamer-binding protein Oct- 1 contains a POU domain with a homeobox subdomain. Genes Dev. 1, 1147-116n.

Suzuki, N., Rohdewohld, H., Neuman, T., Gruss, P., and Schöler, H. R. (1990). OCT-6: a POU transcription factor expressed in embryonal stem cells and in the developing brain. EMBO J. 9, 37233732.

Tanaka, M., and Herr, W. (1990). Differential transcriptional activation by Oct- 1 and Oct-2: interdependent activation domains induce Oct-2 phosphorylation. Cell 60, 375-386.

Thompson, R. F. (1986). Neurobiology of learning and memory. Science 233, 941-947.

Treacy, M. N., He, X., and Rosenfeld, M. G. (1991). I-POU: a POUdomain protein that inhibits neuron-specific gene activation. Nature $350,577-584$.

Verrijzer, C. P., Kal, A. J., and van der Vilet, P. C. (1990). The DNA binding domain (POU domain) of transcription factor Oct-1 suffices for stimulation of DNA replication. EMBO J. 9, 1883-1888. Westin, G., Ciersrer, T., Müller, M. M., Schaffner, G., and Srhaffner, W. (1987). Ovec, a versatile system to study transcription in mammalian cells and cell free extracts. Nucl. Acids Res. 15, 67876798.

Wirth, T., Staudt, L., and Baltimore, D. (1987). An octamer oligonucleotide upstream of a TATA motif is sufficient for lymphoidspecific promoter activity. Nature 329, 174-178.

Wirth, T., Priess, A., Annweiler, A., Zwilling, S., and Oeler, B. (1991). Multiple Oct- 2 isoforms are generated by alternative splicing. Nucl. Acids Res. 19, 43-51. 